\title{
Function Generation with Two Loop Mechanisms Using Decomposition and Correction Method
}

\author{
Gökhan Kiper ${ }^{1, a}$, M. İ. Can Dede ${ }^{a}$, Omar Maaroof ${ }^{a}$, Merve Özkahya ${ }^{a}$ \\ ${ }^{a}$ Mechanical Engineering Department, İzmir Institute of Technology, 35430 İzmir, Turkey
}

\begin{abstract}
Method of decomposition has been successfully applied to function generation with multi-loop mechanisms. For a two-loop mechanism, a function $\mathrm{y}=\mathrm{f}(\mathrm{x})$ can be decomposed into two as $\mathrm{w}=\mathrm{g}(\mathrm{x})$ and $\mathrm{y}=\mathrm{h}(\mathrm{w})=\mathrm{h}(\mathrm{g}(\mathrm{x}))=\mathrm{f}(\mathrm{x})$. This study makes use of the method of decomposition for two-loop mechanisms, where the errors from each loop are forced to match each other. In the first loop, which includes the input of the mechanism, the decomposed function ( $\mathrm{g}$ ) is generated and the resulting structural error is determined. Then, for the second loop, the desired output of the function (f) is considered as an input and the structural error of the decomposed function $(\mathrm{g})$ is determined. By matching the obtained structural errors, the final error in the output of the mechanism is reduced. Three different correction methods are proposed. The first method has three precision points per loop, while the second method has four. In the third method, the extrema of the errors from both loops are matched. The methods are applied to a Watt II type planar six-bar linkage for demonstration. Several numerical examples are worked out and the results are compared with the results in the literature.
\end{abstract}

Keywords: Function generation, decomposition and correction method, Watt II linkage

\section{Introduction}

There are several methods for the kinematic synthesis of function generating mechanisms. Polynomial approximation methods such as interpolation, least squares and Chebyshev approximation methods are some of the commonly used methods [1]. Among these, interpolation approximation method is the easiest one to implement. On the other hand, least squares approximation method provides more accurate approximation with respect to least squares (or L2) norm and Chebyshev approximation method provides more accurate approximation with respect to Chebyshev (or L $\infty$ ) norm, provided that these two methods are applied for a single loop function generator mechanism.

The approximation accuracy in function generating mechanism synthesis can be enhanced by increasing the number of design parameters of the mechanism. This can be accommodated by either of the following methods: 1) introducing artificial frames of reference for the input or output of the mechanism [1]; 2) also considering the amount of displacements of the input or the output link [2]; 3) combining linkages with gears [3]; 4) using a mechanism with more design parameters [4]; 5) using additional loops for a selected mechanism [5]. There are several studies on function generating planar six-link mechanisms. Svoboda [6] considered a Watt II type six-bar linkage as a double three-bar linkage and specified nine design parameters (three link lengths per loop - taking scaling into account and three rotation ranges for the three links connected to the ground). He formulized the function generation problem as composition of two functions corresponding to the two loops, which we call the method of decomposition. He proposes alternative uses of the approach. The first use is such that the first loop is designed to approximately generate the desired function and the second loop is used to tune the result. In the second use, the desired function is decomposed into two identical functions such that

\footnotetext{
${ }^{1}$ Corresponding author. Tel.: +90 232 7506777; fax: +90 2327506701.

E-mail address: gokhankiper@iyte.edu.tr (G. Kiper).
} 
the square root of the function is generated by each of the identical four-bar loops with equal input and output travels. Svoboda calls this latter method as the method of successive approximations. The generalized decomposition method proposed by Alizade et al. [7] allows the decomposition of the function arbitrarily. This enables an extra design parameter for the designer. McLarnan [8] utilized an iterative numerical method for synthesis of planar six-bar linkages for at most 9 precision points with Watt linkages and at most 11 precision points with Stephenson linkages. Rao et al. [9] utilized Burmester theory in order to design six-bar linkages performing function and path generation simultaneously. Several examples of such dual-purpose (combination of function, path, motion generation with the same mechanism) are presented in [10]. Dhingra and Mani [11] derived the input/output (I/O) relationship for Stephenson III and Watt II type planar six-bar linkages and used Newton-Raphson numerical method to solve the function generation synthesis problem with 9 and 11 precision points. Dhingra et al. [12] used homotopy methods for function generation with planar six-bar linkages.

Liu et al. [13] made use of homotopy methods for function generation with six-bar linkages for five precision points. Simionescu and Alexandru [14] worked on the optimal design of Stephenson linkages by increasing the degree-of-freedom to two by removing one of the links. [15] devised a modular approach for design of six-bar function generators. Shiakolas et al. [16] devised a methodology that combines differential evolution and geometric centroid of precision positions technique in order to perform synthesis of Stephenson III type six-bar linkages for dwell and dual-dwell mechanisms with prescribed timing and transmission angle constraints. Kinzel et al. [17] used the so-called geometric constraint programming (GCP) to design a Stephenson III type planar six-bar linkage for function generation with up to 11 precision points. Both graphical and analytical methods are used in GCP and it makes use of commercially available CAD packages to simultaneously meet precision point conditions. Hwang and Chen [18] applied constrained optimization techniques for designing Stephenson II type function generators avoiding order, circuit, and branch defects. Sancibrian [19] made use of an improved version of the generalized reduced gradient optimization method for function generation synthesis of several planar linkages including the Stephenson II, Stephenson III and Watt II type sixbar linkages.

Plecnik and McCarthy [20] also worked on Stephenson II type type of six-bar linkages for function generation with eight precision points. By assuming some of the link lengths, a set of 22 equations with a total degree of 705,432 is obtained. Later on, Plecnik and McCarthy [21] also worked on function generation with a Stephenson II type planar six-bar linkage for 11 precision points. The loop closure equations constitute a set of 70 quadratic equations and the system is reduced to 10 eighth-degree polynomials. The resulting set of equations have a total degree of $1.07 \times 10^{9}$. In both of the last two studies, the equations are solved using continuation method. The latter study resulted in 1,521,037 nonsingular solutions. Agarwal et al. [22] used a genetic-algorithm-based multi-objective optimizer for function generation with a Stephenson-III type planar six-bar linkage. In addition to the structural error defined based on the I/O relationship, the derivative of the structural error is also taken into account, therefore the formulation is called the dual-order formulation. Also, analytical conditions are derived for the identification of the candidate designs which are free of singularities, mobility or branch defects. The numerical examples result in comparable values with the ones that are presented in [20].

All methods mentioned above are based on numerical methods, whereas an analytical formulation is presented in this study. The drawback of the proposed method is that relatively few number of precision points are used. The powerful side of the analytical formulation is that the designer can carry out hundreds of trials in several minutes. Furthermore, the methods proposed in this study allow the designer to tune the design while monitoring several properties such as link length ratios, transmission angle and etc. 
The decomposition method is applicable when there are multiple loops in the generator mechanism and is based on decomposition of the function to be generated into as many functions as the number of loops. Maaroof and Dede [23, 24] have worked on application of the interpolation approximation for a Bennett 6R linkage using the decomposition method. Although interpolation approximation seems to result in inferior results compared to the other two approximation methods, Maaroof et al. [25] showed that superiority of one method over the others is lost when the decomposition method is used.

In this study we apply the decomposition method to a Watt II type planar six-bar mechanism. We propose three correction methods to improve the accuracy of function generation. These methods can be easily and conveniently applied to other two-loop mechanisms, as well. The proposed methods are based on correction of the function generation errors of the first loop in the second loop. Interpolation approximation is used as the synthesis method.

\section{Description of the Mechanism and Function Synthesis Problem}

The Watt II type planar six-bar mechanism is composed of two ternary and four binary links connected to each other by seven revolute joints. In Fig. 1, the input of the mechanism is the $\phi$ angle and the output is $\psi$ angle. $\gamma$ angle is the output of the first loop and will be used as an intermediate variable. A Cartesian coordinate frame with origin at $A_{0}$ is to be used such that the $\mathrm{x}$-axis passes through $\mathrm{B}_{0}$. The input angle $\phi$ and the intermediate angle $\gamma$ are measured from their respective fixed reference axes which make angles of $\phi^{*}$ and $\gamma^{*}$, respectively with the x-axis. The fixed reference axis of the output angle $\psi$ makes an angle of $\psi^{*}$ with respect to $\mathrm{B}_{0} \mathrm{D}_{0}$ direction. In general, $\phi^{*}, \gamma^{*}$ and $\psi^{*}$ are design parameters to be determined via synthesis. Since the I/O relationship of a mechanism with revolute joints does not change when the mechanism is scaled, the four bar loops $\mathrm{A}_{0} \mathrm{ABB}_{0}$ and $\mathrm{B}_{0} \mathrm{CDD}_{0}$ can be independently resized arbitrarily. So, without loss of generality we may assume $\left|A_{0} B_{0}\right|=\left|B_{0} D_{0}\right|=1$ for the fixed link lengths. The other link lengths of the mechanism are denoted as $\left|A_{0} A\right|=a,|A B|=b,\left|B_{0} B\right|$ $=\mathrm{c},\left\llcorner\mathrm{BB}_{0} \mathrm{C}=\alpha, \measuredangle \mathrm{D}_{0} \mathrm{~B}_{0} \mathrm{x}=\beta,\left|\mathrm{B}_{0} \mathrm{C}\right|=\mathrm{d},|\mathrm{CD}|=\mathrm{e}\right.$ and $\left|\mathrm{D}_{0} \mathrm{D}\right|=\mathrm{f}$. A careful inspection shows that angles $\alpha$ and $\beta$ are not independent design parameters, but $\alpha+\beta$ is effective in the I/O relationship of four-bar loop $\mathrm{B}_{0} \mathrm{CDD}_{0}$, because the effective input of the loop is $\angle \mathrm{CB}_{0} \mathrm{D}_{0}=\gamma+\gamma^{*}-(\alpha+\beta)$. $\beta$ also contributes to the reference axis angle $\psi^{*}$ of the output link $\mathrm{D}_{0} \mathrm{D}$, but it just acts as a constant offset to the output angle. Since $\alpha$ and $\beta$ do not independently effect the I/O relationship, without loss of generality we assume $\measuredangle \mathrm{B}_{0} \mathrm{~A}_{0} \mathrm{D}_{0}=\beta=0$ during our analyses. If the designer wishes to make use of a nonzero $\beta$, it is sufficient to replace $\alpha$ by $\alpha-\beta$. Assigning $\beta$ a nonzero value is just rotating the $\mathrm{B}_{0} \mathrm{CDD}_{0}$ by an angle $\beta$ without affecting the I/O relationship of the loop. Note that neither taking $\left|\mathrm{A}_{0} \mathrm{~B}_{0}\right|=\left|\mathrm{B}_{0} \mathrm{D}_{0}\right|=1$ or $\beta=0$ loses generality of the function generation synthesis problem. Also, for computational ease we assume $\gamma^{*}=\beta$ ( $=0$ during the computations) and $\psi^{*}=0$ in this study. The readers can examine [4] to learn about the tools for handling nonzero intermediate $\left(\gamma^{*}\right)$ and output $\left(\psi^{*}\right)$ reference angles.

The I/O relationships for the loops will be derived separately for different correction methods, because the angle $\phi^{*}$ and/or $\alpha$ will be assumed zero in some of the methods.

We want to generate $\mathrm{y}=\mathrm{f}(\mathrm{x})$ for $\mathrm{x}_{0} \leq \mathrm{x} \leq \mathrm{x}_{\mathrm{f}}$ using the Watt II type planar six-bar linkage. We decompose $\mathrm{f}()$ function into two as $\mathrm{w}=\mathrm{g}(\mathrm{x})$ and $\mathrm{y}=\mathrm{h}(\mathrm{w})=\mathrm{h}(\mathrm{g}(\mathrm{x}))=\mathrm{f}(\mathrm{x}) \cdot \mathrm{g}()$ function may be selected arbitrarily. Initial and final values of $w$ and $y$ are found as $w_{0}=g\left(x_{0}\right), w_{f}=g\left(x_{f}\right), y_{0}=f\left(x_{0}\right)$ and $y_{f}=$ $\mathrm{f}\left(\mathrm{x}_{\mathrm{f}}\right)$. Also let $\Delta \mathrm{x}=\mathrm{x}_{\mathrm{f}}-\mathrm{x}_{0}, \Delta \mathrm{w}=\mathrm{w}_{\mathrm{f}}-\mathrm{w}_{0}$ and $\Delta \mathrm{y}=\mathrm{y}_{\mathrm{f}}-\mathrm{y}_{0}$. We associate function variables $\mathrm{x}, \mathrm{w}, \mathrm{y}$ with mechanism variables $\phi, \gamma, \psi$ linearly as

$$
\frac{\phi-\phi_{0}}{\Delta \phi}=\frac{\mathrm{x}-\mathrm{x}_{0}}{\Delta \mathrm{x}}, \frac{\gamma-\gamma_{0}}{\Delta \gamma}=\frac{\mathrm{w}-\mathrm{w}_{0}}{\Delta \mathrm{w}}, \frac{\psi-\psi_{0}}{\Delta \psi}=\frac{\mathrm{y}-\mathrm{y}_{0}}{\Delta \mathrm{y}}
$$




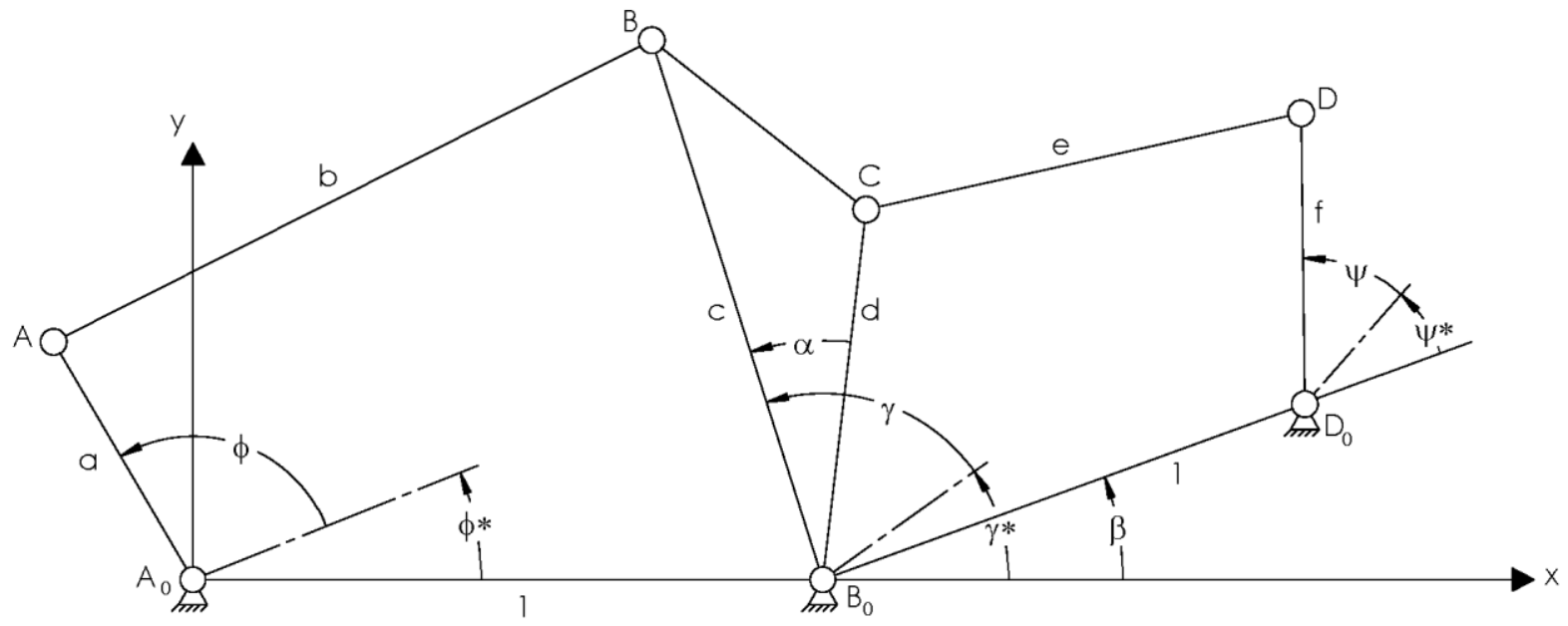

Fig. 1 Kinematic diagram of a Watt II linkage

where $\phi_{0} \leq \phi \leq \phi_{\mathrm{f}}, \gamma_{0} \leq \gamma \leq \gamma_{\mathrm{f}}, \psi_{0} \leq \psi \leq \psi_{\mathrm{f}}$ and $\Delta \phi=\phi_{\mathrm{f}}-\phi_{0}, \Delta \gamma=\gamma_{\mathrm{f}}-\gamma_{0}, \Delta \psi=\psi_{\mathrm{f}}-\psi_{0}$. The limits of the angles are chosen arbitrarily. From Eq. (1), desired mechanism variables $\phi, \gamma, \psi$ can be determined in terms of function variables $\mathrm{x}, \mathrm{w}, \mathrm{y}$ as follows:

$$
\phi=\frac{\Delta \phi}{\Delta \mathrm{x}}\left(\mathrm{x}-\mathrm{x}_{0}\right)+\phi_{0}, \gamma=\frac{\Delta \gamma}{\Delta \mathrm{w}}\left(\mathrm{w}-\mathrm{w}_{0}\right)+\gamma_{0}, \psi=\frac{\Delta \psi}{\Delta \mathrm{y}}\left(\mathrm{y}-\mathrm{y}_{0}\right)+\psi_{0}
$$

Eq. (2) is used for determining the precision points for interpolation approximation. The precision points can be selected with equal spacing, Chebyshev spacing or any other spacing. Usually Chebyshev spacing gives good results. Conversely, $\mathrm{x}, \mathrm{w}, \mathrm{y}$ can be determined in terms of $\phi, \gamma, \psi$ as follows

$$
\mathrm{x}=\frac{\Delta \mathrm{x}}{\Delta \phi}\left(\phi-\phi_{0}\right)+\mathrm{x}_{0}, \mathrm{w}=\frac{\Delta \mathrm{w}}{\Delta \gamma}\left(\gamma-\gamma_{0}\right)+\mathrm{w}_{0}, \mathrm{y}=\frac{\Delta \mathrm{y}}{\Delta \psi}\left(\psi-\psi_{0}\right)+\mathrm{y}_{0}
$$

Eq. (3) is used after the synthesis is performed in order to check the error in between the desired $y(x)$ and the generated $\mathrm{y}(\psi)$.

\section{Correction Methods}

In this section, three correction methods are presented for function generation with a Watt II type planar six-bar linkage. The first correction method involves only the link lengths of the mechanism while the second correction method involves angle references also as extra design parameters. The precision points of the two loops are matched in these two correction methods. In the third correction method, the synthesis of the first loop is the same as the other methods; however precision points of the first loop are not used in the second loop. Instead, the points which correspond to the extrema of the error in the first loop are used for the second loop.

\subsection{Correction Method 1}

The first correction method is the most basic one. In Fig. 1 assume $\phi^{*}=0$ and $\alpha=0$. For loop $\mathrm{A}_{0} \mathrm{ABB}_{0}$ the $\mathrm{I} / \mathrm{O}$ relationship is obtained as follows 


$$
\begin{aligned}
|\overrightarrow{A B}|= & \left|\overrightarrow{A_{o} B}-\overrightarrow{A_{o} A}\right| \Rightarrow b^{2}=(1+c \cos \gamma-a \cos \phi)^{2}+(c \sin \gamma-a \sin \phi)^{2} \\
& \Rightarrow b^{2}-1-a^{2}-c^{2}+2 a \cos \phi+2 a c \cos (\gamma-\phi)=2 c \cos \gamma
\end{aligned}
$$

Eq. (4) can be written in the polynomial form as

$$
\sum_{j=1}^{n} P_{j} f_{j}\left(\mathbf{x}_{i}\right)-F\left(\mathbf{x}_{i}\right)=0 \text { for } \mathrm{i}=1, \ldots, m
$$

where $\mathrm{m}=\mathrm{n}=3, \mathbf{x}_{\mathrm{i}}=\left\{\phi_{\mathrm{i}}, \gamma_{\mathrm{i}}\right\}, \mathrm{P}_{1}=-\frac{1+\mathrm{a}^{2}-\mathrm{b}^{2}+\mathrm{c}^{2}}{2 \mathrm{c}}, \mathrm{P}_{2}=\frac{\mathrm{a}}{\mathrm{c}}, \mathrm{P}_{3}=\mathrm{a}, \mathrm{f}_{1}\left(\mathbf{x}_{\mathbf{i}}\right)=1, \mathrm{f}_{2}\left(\mathbf{x}_{\mathbf{i}}\right)=\cos \phi$, $\mathrm{f}_{3}\left(\mathbf{x}_{\mathbf{i}}\right)=\cos (\gamma-\phi)$ and $\mathrm{F}\left(\mathbf{x}_{\mathbf{i}}\right)=\mathrm{c} \gamma$ for Eq. (4). For three precision points $\mathbf{x}_{1}, \mathbf{x}_{2}, \mathbf{x}_{3}$, Eq. (5) results in a linear set of equations:

$$
\begin{aligned}
& P_{1}+P_{2} \cos \phi_{1}+P_{3} \cos \left(\gamma_{1}-\phi_{1}\right)=\cos \gamma_{1} \\
& P_{1}+P_{2} \cos \phi_{2}+P_{3} \cos \left(\gamma_{2}-\phi_{2}\right)=\cos \gamma_{2} \\
& P_{1}+P_{2} \cos \phi_{3}+P_{3} \cos \left(\gamma_{3}-\phi_{3}\right)=\cos \gamma_{3}
\end{aligned} \Rightarrow\left[\begin{array}{l}
P_{1} \\
P_{2} \\
P_{3}
\end{array}\right]=\left[\begin{array}{ccc}
1 & \cos \phi_{1} & \cos \left(\gamma_{1}-\phi_{1}\right) \\
1 & \cos \phi_{2} & \cos \left(\gamma_{2}-\phi_{2}\right) \\
1 & \cos \phi_{3} & \cos \left(\gamma_{3}-\phi_{3}\right)
\end{array}\right]^{-1}\left[\begin{array}{l}
\cos \gamma_{1} \\
\cos \gamma_{2} \\
\cos \gamma_{3}
\end{array}\right]
$$

Once $\mathrm{P}_{1}, \mathrm{P}_{2}, \mathrm{P}_{3}$ are found from Eq. (6), a, b, c can be uniquely determined as $\mathrm{a}=\mathrm{P}_{3}, \mathrm{c}=\mathrm{a} / \mathrm{P}_{2}$ and $\mathrm{b}=\sqrt{1+\mathrm{a}^{2}+\mathrm{c}^{2}+2 \mathrm{cP}}$, provided that $\mathrm{b}$ is real. If a gets a negative value, one can add $\pi$ to the assumed limits $\left(\phi_{0}\right.$ and $\left.\phi_{\mathrm{f}}\right)$ of $\phi$ in order to make a get a positive value. Similar argument is valid for $\mathrm{c}$ and limits $\left(\gamma_{0}\right.$ and $\left.\gamma_{\mathrm{f}}\right)$ of $\gamma$. Analyzing the resulting four-bar loop with the designed link length parameters, the generated $\gamma$ angle values corresponding to the desired $\phi$ angle values can be calculated from which the generated $w$ values can be determined. One should be careful about the assembly mode of the loop. Let $\delta_{1}=\mathrm{w}_{\text {desired }}-\mathrm{w}_{\text {generated } 1}$ represent the error in loop $\mathrm{A}_{0} \mathrm{ABB}_{0}$. The error curve $\delta_{1}$ versus $\mathrm{x}$ will be as in Fig. 2.

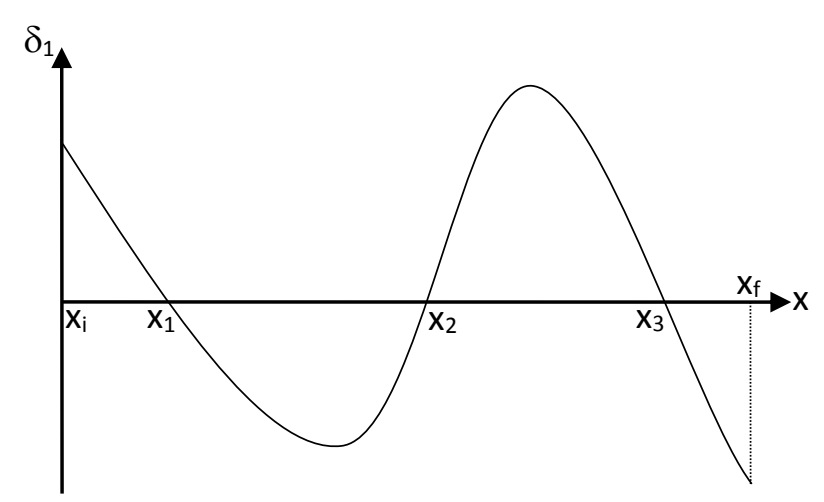

Fig. 2. Error curve for loop $\mathrm{A}_{0} \mathrm{ABB}_{0}$

Although $\psi$ is the output of the mechanism, for loop $\mathrm{B}_{0} \mathrm{CDD}_{0}$ we shall assume $\psi$ is given and resulting $\gamma$ is monitored in order for the errors of the two loops be comparable. Therefore, for loop $\mathrm{B}_{0} \mathrm{CDD}_{0}$, the error in the intermediate variable $\mathrm{w}$ will be monitored as well. Let $\delta_{2}=\mathrm{w}_{\text {desired }}-\mathrm{w}_{\text {generated2 }}$ represent the error value calculated for given desired y and corresponding $\psi$ angle values. For the synthesis we will 
use the same precision points as the first loop and try to approximately equate $\delta_{2}$ and $\delta_{1}$. The I/O relationship for the loop $\mathrm{B}_{0} \mathrm{CDD}_{0}$ is obtained as

$$
\begin{gathered}
|\overrightarrow{C D}|=\left|\overrightarrow{D_{o} D}-\overrightarrow{B_{o} C}\right| \Rightarrow e^{2}=(1+f \cos \psi-\mathrm{d} \cos \gamma)^{2}+(\mathrm{f} \sin \psi-\mathrm{d} \sin \gamma)^{2} \\
\Rightarrow \frac{1+\mathrm{d}^{2}-\mathrm{e}^{2}+\mathrm{f}^{2}}{2 \mathrm{~d}}+\frac{\mathrm{f}}{\mathrm{d}} \cos \psi-\mathrm{f} \cos (\psi-\gamma)=\cos \gamma
\end{gathered}
$$

Eq. (7) can be written in polynomial form (5) with $\mathrm{m}=\mathrm{n}=3, \mathbf{x}_{\mathrm{i}}=\left\{\gamma_{\mathrm{i}}, \psi_{\mathrm{i}}\right\}, \mathrm{P}_{4}=\frac{1+\mathrm{d}^{2}-\mathrm{e}^{2}+\mathrm{f}^{2}}{2 \mathrm{~d}}$, $\mathrm{P}_{5}=\frac{\mathrm{f}}{\mathrm{d}}, \mathrm{P}_{6}=\mathrm{f}, \mathrm{f}_{4}\left(\mathbf{x}_{\mathrm{i}}\right)=1, \mathrm{f}_{5}\left(\mathbf{x}_{\mathrm{i}}\right)=\mathrm{c} \psi_{\mathrm{i}}, \mathrm{f}_{6}\left(\mathbf{x}_{\mathrm{i}}\right)=-\mathrm{c}\left(\psi_{\mathrm{i}}-\gamma_{\mathrm{i}}\right)$ and $\mathrm{F}\left(\mathbf{x}_{\mathrm{i}}\right)=\mathrm{c} \gamma_{\mathrm{i}}$. The three precision points are selected such that the $\gamma$ angles coincide with those of the precision points of loop $\mathrm{A}_{0} \mathrm{ABB}_{0}$. The linear equations can be solved as

$$
\begin{aligned}
& \mathrm{P}_{4}+\cos \psi_{1} \mathrm{P}_{5}-\cos \left(\psi_{1}-\gamma_{1}\right) \mathrm{P}_{6}=\cos \gamma_{1} \\
& \mathrm{P}_{4}+\cos \psi_{3} \mathrm{P}_{5}-\cos \left(\psi_{3}-\gamma_{3}\right) \mathrm{P}_{6}=\cos \gamma_{3} \\
& \mathrm{P}_{4}+\cos \psi_{5} \mathrm{P}_{5}-\cos \left(\psi_{5}-\gamma_{5}\right) \mathrm{P}_{6}=\cos \gamma_{5}
\end{aligned} \Rightarrow\left[\begin{array}{l}
\mathrm{P}_{4} \\
\mathrm{P}_{5} \\
\mathrm{P}_{6}
\end{array}\right]=\left[\begin{array}{ccc}
1 & \cos \psi_{1} & -\cos \left(\psi_{1}-\gamma_{1}\right) \\
1 & \cos \psi_{3} & -\cos \left(\psi_{3}-\gamma_{3}\right) \\
1 & \cos \psi_{5} & -\cos \left(\psi_{5}-\gamma_{5}\right)
\end{array}\right]^{-1}\left[\begin{array}{l}
\cos \gamma_{1} \\
\cos \gamma_{3} \\
\cos \gamma_{5}
\end{array}\right]
$$

After $\mathrm{P}_{4}, \mathrm{P}_{5}$ and $\mathrm{P}_{6}$ are found, the design parameters of the loop can be uniquely determined as $\mathrm{f}=\mathrm{P}_{6}$, $\mathrm{d}=\mathrm{f} / \mathrm{P}_{5}$ and $\mathrm{e}=\sqrt{1+\mathrm{d}^{2}+\mathrm{f}^{2}-2 \mathrm{dP}_{4}}$, provided that $\mathrm{e}$ is real. If $\mathrm{d}$ receives a negative value, this means that $\alpha=\pi$ instead of $\alpha=0$, which is acceptable. If $\mathrm{f}$ is negative, then one can add $\pi$ to the assumed limits $\left(\psi_{0}\right.$ and $\psi_{\mathrm{f}}$ ) of the output angle $\psi$ to force $\mathrm{f}$ to be positive. Analyzing the resulting four-bar loop with the designed link length parameters, the generated $\gamma$ angle values corresponding to the desired $\phi$ angle values and hence the generated w values can be determined. Representative error curves $\delta_{1}$ and $\delta_{2}$ versus $x$ are illustrated in Fig. 3. As a result of the whole design process, the $\psi$ angle values as the output of the mechanism will result in corresponding y values as the output of the generated function. For given $\mathrm{x}$, and hence corresponding angle $\phi$, the error $\delta_{\mathrm{y}}=\mathrm{y}_{\text {desired }}-\mathrm{y}_{\text {generated }}$ variance is also depicted in Fig. 3. Definitely $\delta_{\mathrm{y}}=0$ at the precision points $\mathrm{x}_{1}, \mathrm{x}_{2}$ and $\mathrm{x}_{3}$. There may be other points where $\delta_{\mathrm{y}}=0$ whenever $\delta_{1}$ curve intersects $\delta_{2}$, such as the $\mathrm{x}^{*}$ point demonstrated in Fig. 3.

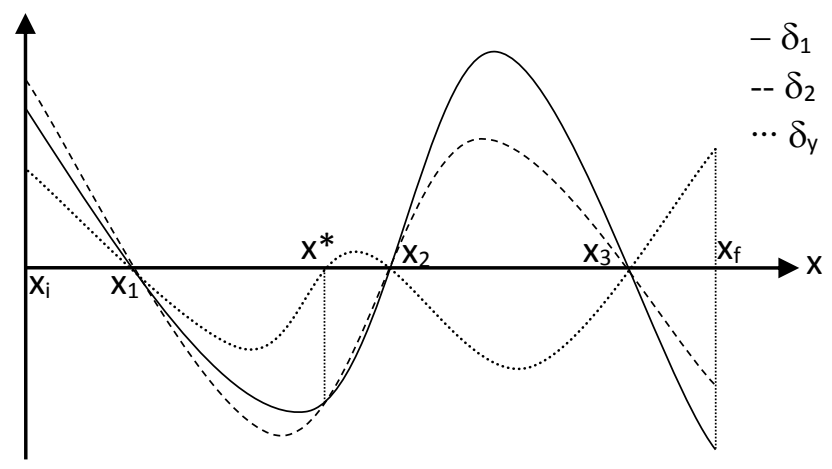

Fig. 3. Error curves for the two loops and function output

The resemblance of $\delta_{1}$ and $\delta_{2}$ directly effects $\delta_{\mathrm{y}}$. In order to obtain lower amounts of $\delta_{\mathrm{y}}$, the designer has several parameters to adjust. The limits $\phi_{0}, \phi_{\mathrm{f}}, \gamma_{0}, \gamma_{\mathrm{f}}, \psi_{0}$ and $\psi_{\mathrm{f}}$ are free to choose, unless there are 
some constraints on these parameters. Also, it is possible to adjust the intermediate function $\mathrm{g}(\cdot)$ for most of the functions. If a design environment such as Microsoft Excel ${ }^{\circledR}$ is used, the designer can assign spin buttons for the limits of the angles and the intermediate function parameter. By using these spin buttons, the designer can simultaneously see the tendency of change in the variations of $\delta_{1}, \delta_{2}$ and $\delta_{\mathrm{y}}$. Meanwhile the designer can monitor $\left|\delta_{\mathrm{y}}\right|_{\max }$ or root mean square of $\delta_{\mathrm{y}}-$ whichever is convenient and minimize it. While performing these adjustments, it is also possible to monitor certain design considerations such as maximum link length to minimum link length, transmission angles, etc.

\subsection{Correction Method 2}

In the second correction method, $\phi^{*}$ and $\alpha$ are assumed nonzero. In this case, the I/O equation for loop $\mathrm{A}_{0} \mathrm{ABB}_{0}$ becomes

$$
\begin{aligned}
& |\overrightarrow{\mathrm{AB}}|=\left|\overrightarrow{\mathrm{A}_{\mathrm{o}} \mathrm{B}}-\overrightarrow{\mathrm{A}_{\mathrm{o}} \mathrm{A}}\right| \Rightarrow \mathrm{b}^{2}=\left(1+\mathrm{cc} \gamma-\mathrm{ac}\left(\phi+\phi^{*}\right)\right)^{2}+\left(\operatorname{cs} \gamma-\operatorname{as}\left(\phi+\phi^{*}\right)\right)^{2} \\
& \Rightarrow-\frac{1+\mathrm{a}^{2}-\mathrm{b}^{2}+\mathrm{c}^{2}}{2 \mathrm{c}}+\frac{\mathrm{a}}{\mathrm{c}} \mathrm{c} \phi^{*} \mathrm{c} \phi-\frac{\mathrm{a}}{\mathrm{c}} \mathrm{s} \phi^{*} \mathrm{~s} \phi+\operatorname{ac} \phi^{*} \mathrm{c}(\gamma-\phi)+\operatorname{as} \phi^{*} \mathrm{~s}(\gamma-\phi)=\mathrm{c} \gamma
\end{aligned}
$$

Eq. (9) can be written in polynomial form (5) with $\mathrm{m}=4, \mathrm{n}=5, \mathbf{x}_{\mathrm{i}}=\left\{\phi_{\mathrm{i}}, \gamma_{\mathrm{i}}\right\}, \mathrm{P}_{1}=-\frac{1+\mathrm{a}^{2}-\mathrm{b}^{2}+\mathrm{c}^{2}}{2 \mathrm{c}}$, $\mathrm{P}_{2}=\frac{\mathrm{a}}{\mathrm{c}} \mathrm{c} \phi^{*}, \mathrm{P}_{3}=\frac{\mathrm{a}}{\mathrm{c}} \mathrm{s} \phi^{*}, \mathrm{P}_{4}=\mathrm{ac} \phi^{*}, \mathrm{P}_{5}=\mathrm{as} \phi^{*}, \mathrm{f}_{1}\left(\mathbf{x}_{\mathrm{i}}\right)=1, \mathrm{f}_{2}\left(\mathbf{x}_{\mathrm{i}}\right)=\mathrm{c} \phi_{\mathrm{i}}, \mathrm{f}_{3}\left(\mathbf{x}_{\mathrm{i}}\right)=-s \phi_{\mathrm{i}}, \mathrm{f}_{4}\left(\mathbf{x}_{\mathrm{i}}\right)=\mathrm{c}\left(\gamma_{\mathrm{i}}-\phi_{\mathrm{i}}\right)$, $f_{5}\left(\mathbf{x}_{i}\right)=s\left(\gamma_{i}-\phi_{i}\right)$ and $F\left(\mathbf{x}_{i}\right)=c \gamma_{i}$. There are four design parameters ( $a, b, c$ and $\left.\phi^{*}\right)$, so there should be four precision points: $\mathrm{x}_{1}, \mathrm{x}_{2}, \mathrm{x}_{3}$ and $\mathrm{x}_{4}$. However there are five $\mathrm{P}_{\mathrm{j}}$ 's, hence they cannot be independent of each other. Indeed, $\mathrm{P}_{3} \mathrm{P}_{4}=\mathrm{P}_{2} \mathrm{P}_{5}$. The problem can be linearized by using a Lagrange's variable. Let $P_{5}=\lambda$ and $P_{j}=m_{j}+n_{j} \lambda$ for $j=1,2,3,4$, 5. Substituting into the polynomial equations:

$$
\begin{aligned}
& \mathrm{m}_{1}+\mathrm{n}_{1} \lambda+\left(\mathrm{m}_{2}+\mathrm{n}_{2} \lambda\right) \mathrm{c} \phi_{1}-\left(\mathrm{m}_{3}+\mathrm{n}_{3} \lambda\right) \mathrm{s} \phi_{1}+\left(\mathrm{m}_{4}+\mathrm{n}_{4} \lambda\right) \mathrm{c}\left(\gamma_{1}-\phi_{1}\right)=\mathrm{c} \gamma_{1}-\mathrm{s}\left(\gamma_{1}-\phi_{1}\right) \lambda \\
& \mathrm{m}_{1}+\mathrm{n}_{1} \lambda+\left(\mathrm{m}_{2}+\mathrm{n}_{2} \lambda\right) \mathrm{c} \phi_{3}-\left(\mathrm{m}_{3}+\mathrm{n}_{3} \lambda\right) \mathrm{s} \phi_{3}+\left(\mathrm{m}_{4}+\mathrm{n}_{4} \lambda\right) \mathrm{c}\left(\gamma_{3}-\phi_{3}\right)=\mathrm{c} \gamma_{3}-\mathrm{s}\left(\gamma_{3}-\phi_{3}\right) \lambda \\
& \mathrm{m}_{1}+\mathrm{n}_{1} \lambda+\left(\mathrm{m}_{2}+\mathrm{n}_{2} \lambda\right) \mathrm{c} \phi_{5}-\left(\mathrm{m}_{3}+\mathrm{n}_{3} \lambda\right) \mathrm{s} \phi_{5}+\left(\mathrm{m}_{4}+\mathrm{n}_{4} \lambda\right) \mathrm{c}\left(\gamma_{5}-\phi_{5}\right)=\mathrm{c} \gamma_{5}-\mathrm{s}\left(\gamma_{5}-\phi_{5}\right) \lambda \\
& \mathrm{m}_{1}+\mathrm{n}_{1} \lambda+\left(\mathrm{m}_{2}+\mathrm{n}_{2} \lambda\right) \mathrm{c} \phi_{7}-\left(\mathrm{m}_{3}+\mathrm{n}_{3} \lambda\right) \mathrm{s} \phi_{7}+\left(\mathrm{m}_{4}+\mathrm{n}_{4} \lambda\right) \mathrm{c}\left(\gamma_{7}-\phi_{7}\right)=\mathrm{c} \gamma_{7}-\mathrm{s}\left(\gamma_{7}-\phi_{7}\right) \lambda
\end{aligned}
$$

In order for Eqs. (10) to be satisfied, the coefficients of $\lambda$ and the rest of each equation need to be equated to zero. In matrix form:

$$
\left[\begin{array}{llll}
1 & c \phi_{1} & -s \phi_{1} & \mathrm{c}\left(\gamma_{1}-\phi_{1}\right) \\
1 & \mathrm{c} \phi_{3} & -\mathrm{s} \phi_{3} & \mathrm{c}\left(\gamma_{3}-\phi_{3}\right) \\
1 & \mathrm{c} \phi_{5} & -\mathrm{s} \phi_{5} & \mathrm{c}\left(\gamma_{5}-\phi_{5}\right) \\
1 & \mathrm{c} \phi_{7} & -\mathrm{s} \phi_{7} & \mathrm{c}\left(\gamma_{7}-\phi_{7}\right)
\end{array}\right]\left[\begin{array}{l}
\mathrm{m}_{1} \\
\mathrm{~m}_{2} \\
\mathrm{~m}_{3} \\
\mathrm{~m}_{4}
\end{array}\right]=\left[\begin{array}{l}
\mathrm{c} \gamma_{1} \\
\mathrm{c} \gamma_{3} \\
\mathrm{c} \gamma_{5} \\
\mathrm{c} \gamma_{7}
\end{array}\right] \text { and }\left[\begin{array}{cccc}
1 & \mathrm{c} \phi_{1} & -\mathrm{s} \phi_{1} & \mathrm{c}\left(\gamma_{1}-\phi_{1}\right) \\
1 & \mathrm{c} \phi_{3} & -\mathrm{s} \phi_{3} & \mathrm{c}\left(\gamma_{3}-\phi_{3}\right) \\
1 & \mathrm{c} \phi_{5} & -\mathrm{s} \phi_{5} & \mathrm{c}\left(\gamma_{5}-\phi_{5}\right) \\
1 & \mathrm{c} \phi_{7} & -\mathrm{s} \phi_{7} & \mathrm{c}\left(\gamma_{7}-\phi_{7}\right)
\end{array}\right]\left[\begin{array}{l}
\mathrm{n}_{1} \\
\mathrm{n}_{2} \\
\mathrm{n}_{3} \\
\mathrm{n}_{4}
\end{array}\right]=\left[\begin{array}{l}
-\mathrm{s}\left(\gamma_{1}-\phi_{1}\right) \\
-\mathrm{s}\left(\gamma_{3}-\phi_{3}\right) \\
-\mathrm{s}\left(\gamma_{5}-\phi_{5}\right) \\
-\mathrm{s}\left(\gamma_{7}-\phi_{7}\right)
\end{array}\right]
$$

$\mathrm{m}_{1}, \mathrm{~m}_{2}, \mathrm{~m}_{3}, \mathrm{~m}_{4}, \mathrm{n}_{1}, \mathrm{n}_{2}, \mathrm{n}_{3}$ and $\mathrm{n}_{4}$ are solved by matrix inversion. $\lambda$ is solved as follows: 


$$
\begin{gathered}
\mathrm{P}_{3} \mathrm{P}_{4}=\mathrm{P}_{2} \mathrm{P}_{5}=\left(\mathrm{m}_{3}+\mathrm{n}_{3} \lambda\right)\left(\mathrm{m}_{4}+\mathrm{n}_{4} \lambda\right)=\left(\mathrm{m}_{2}+\mathrm{n}_{2} \lambda\right) \lambda \\
\Rightarrow\left(\mathrm{n}_{3} \mathrm{n}_{4}-\mathrm{n}_{2}\right) \lambda^{2}+\left(\mathrm{m}_{3} \mathrm{n}_{4}+\mathrm{n}_{3} \mathrm{~m}_{4}-\mathrm{m}_{2}\right) \lambda+\mathrm{m}_{3} \mathrm{~m}_{4}=0 \\
\Rightarrow \lambda=\frac{\mathrm{m}_{2}-\mathrm{m}_{3} \mathrm{n}_{4}-\mathrm{n}_{3} \mathrm{~m}_{4} \mp \sqrt{\left(\mathrm{m}_{3} \mathrm{n}_{4}+\mathrm{n}_{3} \mathrm{~m}_{4}-\mathrm{m}_{2}\right)^{2}-4 \mathrm{~m}_{3} \mathrm{~m}_{4}\left(\mathrm{n}_{3} \mathrm{n}_{4}-\mathrm{n}_{2}\right)}}{2\left(\mathrm{n}_{3} \mathrm{n}_{4}-\mathrm{n}_{2}\right)}
\end{gathered}
$$

Next, $\mathrm{P}_{\mathrm{j}}=\mathrm{m}_{\mathrm{j}}+\mathrm{n}_{\mathrm{j}} \lambda$ for $\mathrm{j}=1,2,3,4$ are evaluated. After determining $\mathrm{P}_{1}, \mathrm{P}_{2}, \mathrm{P}_{3}, \mathrm{P}_{4}, \mathrm{P}_{5}, \mathrm{a}=\sqrt{\mathrm{P}_{4}^{2}+\mathrm{P}_{5}^{2}}$, $\phi^{*}=\operatorname{atan} 2\left(\mathrm{P}_{4}, \mathrm{P}_{5}\right), \quad \mathrm{c}=\mathrm{ac} \phi^{*} / \mathrm{P}_{2}$ and $\mathrm{b}=\sqrt{1+\mathrm{a}^{2}+\mathrm{c}^{2}+2 \mathrm{c} \mathrm{P}_{1}}$. All design parameters are uniquely determined provided that $\mathrm{b}$ is real. If $\mathrm{c}$ is negative, limits of $\gamma$ should be increased by $\pi$. The resulting error variation $\delta_{1}=\mathrm{w}_{\text {desired }}-\mathrm{w}_{\text {generated } 1}$ has at least four precision points $\left(\mathrm{x}_{1}, \mathrm{x}_{2}, \mathrm{x}_{3}\right.$ and $\left.\mathrm{x}_{4}\right)$ if the correct assembly mode of the four bar loop is selected.

For loop $\mathrm{B}_{0} \mathrm{CDD}_{0}$ the $\mathrm{I} / \mathrm{O}$ relationship is obtained as

$$
\begin{gathered}
|\overrightarrow{\mathrm{CD}}|=\left|\overrightarrow{\mathrm{D}_{\mathrm{o}} \mathrm{D}}-\overrightarrow{\mathrm{B}_{\mathrm{o}} \mathrm{C}}\right| \Rightarrow \mathrm{e}^{2}=(1+\mathrm{fc} \psi-\mathrm{dc}(\gamma-\alpha))^{2}+(\mathrm{fs} \psi-\mathrm{ds}(\gamma-\alpha))^{2} \\
\Rightarrow \frac{1+\mathrm{d}^{2}-\mathrm{e}^{2}+\mathrm{f}^{2}}{2 \mathrm{dc} \alpha}+\frac{\mathrm{f}}{\mathrm{dc} \alpha} \mathrm{c} \psi-\mathrm{fc}(\psi-\gamma)-\mathrm{t} \alpha \mathrm{s} \gamma+\mathrm{ft} \alpha \mathrm{s}(\psi-\gamma)=\mathrm{c} \gamma
\end{gathered}
$$

Eq. (13) can be written in polynomial form (5) with $\mathrm{m}=4, \mathrm{n}=5, \mathbf{x}_{\mathrm{i}}=\left\{\gamma_{\mathrm{i}}, \psi_{\mathrm{i}}\right\}, \mathrm{P}_{6}=\frac{1+\mathrm{d}^{2}-\mathrm{e}^{2}+\mathrm{f}^{2}}{2 \mathrm{dc} \alpha}$, $\mathrm{P}_{7}=\frac{\mathrm{f}}{\mathrm{dc} \alpha}, \mathrm{P}_{8}=\mathrm{f}, \mathrm{P}_{9}=\mathrm{t} \alpha, \mathrm{P}_{10}=\mathrm{ft} \alpha, \mathrm{f}_{6}\left(\mathbf{x}_{\mathrm{i}}\right)=1, \mathrm{f}_{7}\left(\mathbf{x}_{\mathrm{i}}\right)=\mathrm{c} \psi_{\mathrm{i}}, \mathrm{f}_{8}\left(\mathbf{x}_{\mathrm{i}}\right)=-\mathrm{c}\left(\psi_{\mathrm{i}}-\gamma_{\mathrm{i}}\right), \mathrm{f}_{9}\left(\mathbf{x}_{\mathrm{i}}\right)=-s \gamma_{\mathrm{i}}$, $\mathrm{f}_{10}\left(\mathbf{x}_{\mathrm{i}}\right)=\mathrm{s}\left(\psi_{\mathrm{i}}-\gamma_{\mathrm{i}}\right)$ and $\mathrm{F}\left(\mathbf{x}_{\mathrm{i}}\right)=\mathrm{c} \gamma_{\mathrm{i}}$. There are four design parameters $(\mathrm{d}, \mathrm{e}, \mathrm{f}$ and $\alpha)$ and hence four precision points $\mathrm{x}_{1}, \mathrm{x}_{2}, \mathrm{x}_{3}$ and $\mathrm{x}_{4}$. The same precision points for loop $\mathrm{A}_{0} \mathrm{ABB}_{0}$ are used and corresponding $\gamma_{i}$ and $\psi_{i}$ angles for $\mathrm{i}=1,2,3,4$ are to be used. There are five $\mathrm{P}_{\mathrm{j}}$ 's, but $\mathrm{P}_{10}=\mathrm{P}_{8} \mathrm{P}_{9}$. Let $P_{10}=\lambda$ and $P_{j}=m_{j}+n_{j} \lambda$ for $j=6,7,8,9$. Substituting into the polynomial equations:

$$
\begin{aligned}
& \left(\mathrm{m}_{6}+\mathrm{n}_{6} \lambda\right)+\left(\mathrm{m}_{7}+\mathrm{n}_{7} \lambda\right) \mathrm{c} \psi_{1}-\left(\mathrm{m}_{8}+\mathrm{n}_{8} \lambda\right) \mathrm{c}\left(\psi_{1}-\gamma_{1}\right)-\left(\mathrm{m}_{9}+\mathrm{n}_{9} \lambda\right) \mathrm{s} \gamma_{1}=\mathrm{c} \gamma_{1}-\mathrm{s}\left(\psi_{1}-\gamma_{1}\right) \lambda \\
& \left(\mathrm{m}_{6}+\mathrm{n}_{6} \lambda\right)+\left(\mathrm{m}_{7}+\mathrm{n}_{7} \lambda\right) \mathrm{c} \psi_{3}-\left(\mathrm{m}_{8}+\mathrm{n}_{8} \lambda\right) \mathrm{c}\left(\psi_{3}-\gamma_{3}\right)-\left(\mathrm{m}_{9}+\mathrm{n}_{9} \lambda\right) \mathrm{s} \gamma_{3}=\mathrm{c} \gamma_{3}-\mathrm{s}\left(\psi_{3}-\gamma_{3}\right) \lambda \\
& \left(\mathrm{m}_{6}+\mathrm{n}_{6} \lambda\right)+\left(\mathrm{m}_{7}+\mathrm{n}_{7} \lambda\right) \mathrm{c} \psi_{5}-\left(\mathrm{m}_{8}+\mathrm{n}_{8} \lambda\right) \mathrm{c}\left(\psi_{5}-\gamma_{5}\right)-\left(\mathrm{m}_{9}+\mathrm{n}_{9} \lambda\right) \mathrm{s} \gamma_{5}=\mathrm{c} \gamma_{5}-\mathrm{s}\left(\psi_{5}-\gamma_{5}\right) \lambda \\
& \left(\mathrm{m}_{6}+\mathrm{n}_{6} \lambda\right)+\left(\mathrm{m}_{7}+\mathrm{n}_{7} \lambda\right) \mathrm{c} \psi_{7}-\left(\mathrm{m}_{8}+\mathrm{n}_{8} \lambda\right) \mathrm{c}\left(\psi_{7}-\gamma_{1}\right)_{7}-\left(\mathrm{m}_{9}+\mathrm{n}_{9} \lambda\right) \mathrm{s} \gamma_{7}=\mathrm{c} \gamma_{7}-\mathrm{s}\left(\psi_{7}-\gamma_{7}\right) \lambda
\end{aligned}
$$

Equating coefficients of $\lambda$ and the rest to zero in Eqs. (14) and writing in matrix form:

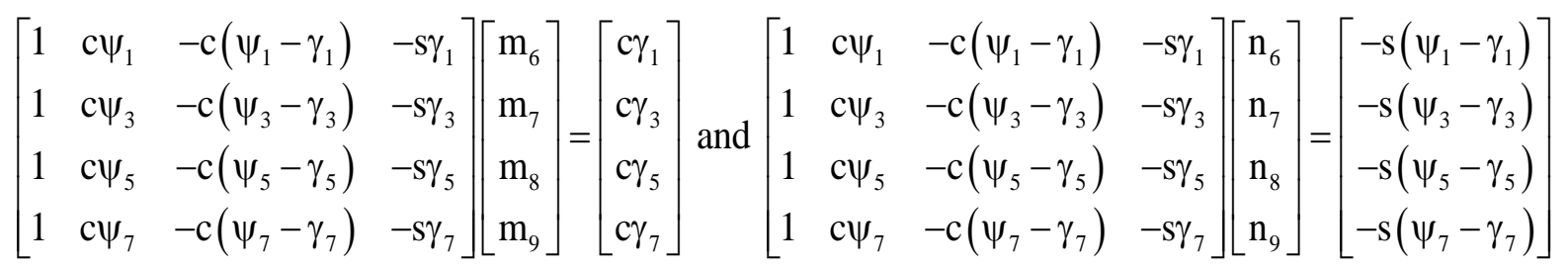

$\mathrm{m}_{6}, \mathrm{~m}_{7}, \mathrm{~m}_{8}, \mathrm{~m}_{9}, \mathrm{n}_{6}, \mathrm{n}_{7}, \mathrm{n}_{8}$ and $\mathrm{n}_{9}$ are solved by matrix inversion. $\lambda$ is solved as follows: 


$$
\begin{gathered}
\lambda=\mathrm{P}_{10}=\mathrm{P}_{8} \mathrm{P}_{9}=\left(\mathrm{m}_{8}+\mathrm{n}_{8} \lambda\right)\left(\mathrm{m}_{9}+\mathrm{n}_{9} \lambda\right) \\
\Rightarrow \mathrm{n}_{8} \mathrm{n}_{9} \lambda^{2}+\left(\mathrm{m}_{8} \mathrm{n}_{9}+\mathrm{n}_{8} \mathrm{~m}_{9}-1\right) \lambda+\mathrm{m}_{8} \mathrm{~m}_{9}=0 \\
\Rightarrow \lambda=\frac{1-\mathrm{m}_{8} \mathrm{n}_{9}-\mathrm{n}_{8} \mathrm{~m}_{9} \mp \sqrt{\left(\mathrm{m}_{8} \mathrm{n}_{9}+\mathrm{n}_{8} \mathrm{~m}_{9}-1\right)^{2}-4 \mathrm{~m}_{8} \mathrm{~m}_{9} \mathrm{n}_{8} \mathrm{n}_{9}}}{2 \mathrm{n}_{8} \mathrm{n}_{9}}
\end{gathered}
$$

Next, $P_{j}=m_{j}+n_{j} \lambda$ for $j=6,7,8,9$ are evaluated. Then, $f=P_{8}, \alpha=\tan ^{-1} P_{9}, d=f /\left(P_{7} c \alpha\right)$ and $\mathrm{e}=\sqrt{1+\mathrm{d}^{2}+\mathrm{f}^{2}-2{\mathrm{dc} \alpha \mathrm{P}_{6}}_{6}}$. Solution results in a mechanism if $\mathrm{e}$ is real. In this case, the solution is not unique, because $\alpha=\tan ^{-1} \mathrm{P}_{9}+\pi$ is also a feasible solution. If $\mathrm{d}$ is positive for $\alpha=\tan ^{-1} \mathrm{P}_{9}, \alpha$ is kept as it is. Otherwise, $\pi$ is added to $\alpha$. If $\mathrm{f}$ is negative, $\pi$ can be added to limits of $\psi$. The error variation $\delta_{2}=$ $\mathrm{W}_{\text {desired }}-\mathrm{W}_{\text {generated2 } 2}$ is determined with at least four precision points with the right assembly mode of the loop. As in the first correction method, $\delta_{\mathrm{y}}=\mathrm{y}_{\text {desired }}-\mathrm{y}_{\text {generated }}$ is obtained and minimized by adjusting the angles and the intermediate function parameter while monitoring the necessary design considerations.

\subsection{Correction Method 3}

In the first two correction methods explained above, numerical examples showed that mostly the maximum error occurs due to the difference in the local extrema of $\delta_{1}$ and $\delta_{2}$. A third correction method is developed to equate local extrema rather than the precision points. In this last correction method, $\phi^{*}=0$, but $\alpha$ is nonzero. In this case, the $\mathrm{I} / \mathrm{O}$ equation for loop $\mathrm{A}_{0} \mathrm{ABB}_{0}$ is given by Eq. (4) and the I/O equation for loop $\mathrm{B}_{0} \mathrm{CDD}_{0}$ is given by Eq. (13). Synthesis is performed for loop $\mathrm{A}_{0} \mathrm{ABB}_{0}$ with three precision points $\mathrm{x}_{1}, \mathrm{x}_{2}$ and $\mathrm{x}_{3}$. The resulting error variation $\delta_{1}=\mathrm{w}_{\text {desired }}-\mathrm{w}_{\text {generated } 1}$ is given once again in Fig. 4, however in this case the two local extrema inside the domain and the corresponding $\mathrm{x}_{4}$ and $\mathrm{x}_{5}$ locations are also shown. $\left(\mathrm{x}_{4}, \delta\left(\mathrm{x}_{4}\right)\right)$ and $\left(\mathrm{x}_{5}, \delta\left(\mathrm{x}_{5}\right)\right)$ points in the error curve in Fig. 4 will be used for the design of loop $\mathrm{B}_{0} \mathrm{CDD}_{0}$.

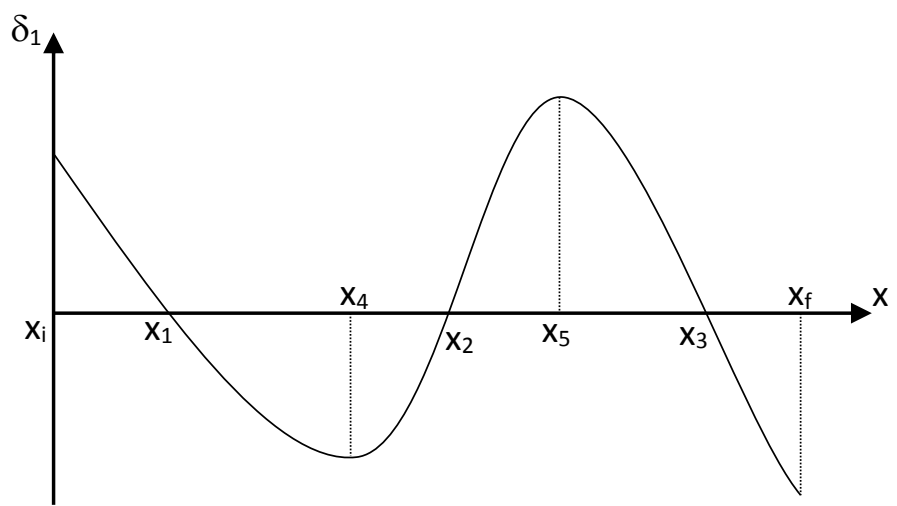

Fig. 4. Error curve for loop $\mathrm{A}_{0} \mathrm{ABB}_{0}$

$\mathrm{x}_{4}$ and $\mathrm{x}_{5}$ are analytically determined from $\frac{\partial \delta_{1}}{\partial \mathrm{x}}=0$ as follows: 


$$
\frac{\partial \delta_{1}}{\partial \mathrm{x}}=\frac{\partial}{\partial \mathrm{x}}\left(\mathrm{w}_{\mathrm{d}}-\mathrm{w}_{\mathrm{g}}\right)=\frac{\partial \mathrm{w}_{\mathrm{d}}}{\partial \mathrm{x}}-\frac{\partial \mathrm{w}_{\mathrm{g}}}{\partial \gamma} \frac{\partial \gamma}{\partial \phi} \frac{\partial \phi}{\partial \mathrm{x}}=\frac{\partial \mathrm{w}_{\mathrm{d}}}{\partial \mathrm{x}}-\frac{\Delta \mathrm{w}_{\mathrm{g}}}{\Delta \gamma} \frac{\Delta \phi}{\Delta \mathrm{x}} \frac{\partial \gamma}{\partial \phi}
$$

where $\mathrm{w}_{\mathrm{d}}$ is $\mathrm{w}_{\text {desired }}$ and $\mathrm{w}_{\mathrm{g}}$ is $\mathrm{w}_{\text {generated } 1 .} \partial \gamma / \partial \phi$ is to be evaluated by differentiating the $\mathrm{I} / \mathrm{O}$ equation of loop $\mathrm{A}_{0} \mathrm{ABB}_{0}$ with respect to $\phi$ :

$$
\begin{gathered}
\mathrm{P}_{1}+\mathrm{P}_{2} \mathrm{c} \phi+\mathrm{P}_{3} \mathrm{c}(\gamma-\phi)=\mathrm{c} \gamma \Rightarrow \mathrm{P}_{2} \mathrm{~s} \phi+\mathrm{P}_{3} \mathrm{~s}(\gamma-\phi)\left(\frac{\partial \gamma}{\partial \phi}-1\right)=\mathrm{s} \gamma \frac{\partial \gamma}{\partial \phi} \\
\Rightarrow \frac{\partial \gamma}{\partial \phi}=\frac{\mathrm{P}_{2} \mathrm{~s} \phi-\mathrm{P}_{3} \mathrm{~s}(\gamma-\phi)}{\mathrm{s} \gamma-\mathrm{P}_{3} \mathrm{~s}(\gamma-\phi)}
\end{gathered}
$$

Substituting in $\partial \delta_{1} / \partial \mathrm{x}$ in Eq. (17) and equating to zero:

$$
\frac{\partial \mathrm{w}_{\mathrm{d}}}{\partial \mathrm{x}}-\frac{\Delta \mathrm{w}_{\mathrm{g}}}{\Delta \gamma} \frac{\Delta \phi}{\Delta \mathrm{x}} \frac{\mathrm{P}_{2} \mathrm{~s} \phi-\mathrm{P}_{3} \mathrm{~s}(\gamma-\phi)}{\mathrm{s} \gamma-\mathrm{P}_{3} \mathrm{~s}(\gamma-\phi)}=0 \Rightarrow \frac{\partial \mathrm{w}_{\mathrm{d}}}{\partial \mathrm{x}} \mathrm{s} \gamma-\frac{\Delta \mathrm{w}_{\mathrm{g}}}{\Delta \gamma} \frac{\Delta \phi}{\Delta \mathrm{x}} \mathrm{s} \phi \mathrm{P}_{2}+\left(\frac{\Delta \mathrm{w}_{\mathrm{g}}}{\Delta \gamma} \frac{\Delta \phi}{\Delta \mathrm{x}}-\frac{\partial \mathrm{w}_{\mathrm{d}}}{\partial \mathrm{x}}\right) \mathrm{s}(\gamma-\phi) \mathrm{P}_{3}=0
$$

Eq. (19) is a nonlinear equation in $\mathrm{x}$ and can be solved for $\mathrm{x}$ using a numerical method. There should be two solutions corresponding to the local extrema inside the domain of $x$. In Excel, the built-in function "Goal Seek" can be used to find the roots. The "Goal Seek" function of Excel is based on the NewtonRaphson root finding algorithm. Also a simple macro can be written inside the spin button codes so that the Goal Seek function is automatically employed when the function limits or the intermediate function parameter are altered. When the initial value for the Goal Seek is set to the previous value of the roots, the convergence is immediate, because the initial value will be very close to the solution.

For loop $\mathrm{B}_{0} \mathrm{CDD}_{0}$ we impose $\delta_{2}\left(\mathrm{x}_{4}\right)=\delta_{1}\left(\mathrm{x}_{4}\right), \delta_{2}\left(\mathrm{x}_{5}\right)=\delta_{1}\left(\mathrm{x}_{5}\right)$ and $\partial \delta_{2} / \partial \mathrm{x}=0$ at both of $\mathrm{x}_{4}$ and $\mathrm{x}_{5}$. The first two conditions are generated from the I/O relationship of loop $\mathrm{B}_{0} \mathrm{CDD}_{0}$ by using generated $\gamma$ values from loop $\mathrm{A}_{0} \mathrm{ABB}_{0}$ and desired $\psi$ corresponding to $\mathrm{x}_{4}$ and $\mathrm{x}_{5}$ :

$$
\begin{aligned}
& \mathrm{P}_{4}+c \psi_{4} \mathrm{P}_{5}-\mathrm{c}\left(\psi_{4}-\gamma_{4}\right) \mathrm{P}_{6}-\mathrm{s} \gamma_{4} \mathrm{P}_{7}+\mathrm{s}\left(\psi_{4}-\gamma_{4}\right) \mathrm{P}_{8}=\mathrm{c} \gamma_{4} \\
& \mathrm{P}_{4}+\mathrm{c} \psi_{5} \mathrm{P}_{5}-\mathrm{c}\left(\psi_{5}-\gamma_{5}\right) \mathrm{P}_{6}-\mathrm{s} \gamma_{5} \mathrm{P}_{7}+\mathrm{s}\left(\psi_{5}-\gamma_{5}\right) \mathrm{P}_{8}=\mathrm{c} \gamma_{5}
\end{aligned}
$$

We need to take derivative of $\delta_{2}$ and equate to zero at $\mathrm{x}_{4}$ and $\mathrm{x}_{5}$ for the extrema conditions:

$$
\frac{\partial \delta_{2}}{\partial \mathrm{x}}=\frac{\partial}{\partial \mathrm{x}}\left(\mathrm{w}_{\mathrm{d}}-\mathrm{w}_{\mathrm{g}}\right)=\frac{\partial \mathrm{w}}{\partial \mathrm{x}}-\frac{\partial \mathrm{w}}{\partial \gamma} \frac{\partial \gamma}{\partial \psi} \frac{\partial \psi}{\partial \mathrm{y}} \frac{\partial \mathrm{y}}{\partial \mathrm{x}}=\frac{\partial \mathrm{w}}{\partial \mathrm{x}}-\frac{\Delta \mathrm{w}}{\Delta \gamma} \frac{\Delta \psi}{\Delta \mathrm{y}} \frac{\partial \mathrm{y}}{\partial \mathrm{x}} \frac{\partial \gamma}{\partial \psi}
$$

where $\mathrm{w}_{\mathrm{d}}$ is $\mathrm{w}_{\text {desired }}$ and $\mathrm{w}_{\mathrm{g}}$ is $\mathrm{w}_{\text {generated2. }} \partial \gamma / \partial \psi$ is to be evaluated by differentiating the $\mathrm{I} / \mathrm{O}$ equation of loop $\mathrm{B}_{0} \mathrm{CDD}_{0}$ with respect to $\psi$ :

$$
\begin{gathered}
\mathrm{P}_{4}+\mathrm{P}_{5} \mathrm{c} \psi-\mathrm{P}_{6} \mathrm{c}(\psi-\gamma)-\mathrm{P}_{7} \mathrm{~s} \gamma+\mathrm{P}_{8} \mathrm{~s}(\psi-\gamma)=\mathrm{c} \gamma \\
\Rightarrow-\mathrm{P}_{5} \mathrm{~s} \psi+\mathrm{P}_{6} \mathrm{~s}(\psi-\gamma)\left(1-\frac{\partial \gamma}{\partial \psi}\right)-\mathrm{P}_{7} \mathrm{c} \gamma \frac{\partial \gamma}{\partial \psi}+\mathrm{P}_{8} \mathrm{c}(\psi-\gamma)\left(1-\frac{\partial \gamma}{\partial \psi}\right)=-\mathrm{s} \gamma \frac{\partial \gamma}{\partial \psi} \\
\Rightarrow \frac{\partial \gamma}{\partial \psi}=\frac{\mathrm{P}_{5} \mathrm{~s} \psi-\mathrm{P}_{6} \mathrm{~s}(\psi-\gamma)-\mathrm{P}_{8} \mathrm{c}(\psi-\gamma)}{\mathrm{s} \gamma-\mathrm{P}_{6} \mathrm{~s}(\psi-\gamma)-\mathrm{P}_{7} \mathrm{c} \gamma-\mathrm{P}_{8} \mathrm{c}(\psi-\gamma)}
\end{gathered}
$$

Substituting in $\partial \delta_{2} / \partial x$ in Eq. (21) and equating to zero: 


$$
\begin{gathered}
\frac{\partial \delta_{2}}{\partial \mathrm{x}}=\frac{\partial \mathrm{w}}{\partial \mathrm{x}}-\frac{\Delta \mathrm{w}}{\Delta \gamma} \frac{\Delta \psi}{\Delta \mathrm{y}} \frac{\partial \mathrm{y}}{\partial \mathrm{x}} \frac{\mathrm{P}_{5} \mathrm{~s} \psi-\mathrm{P}_{6} \mathrm{~s}(\psi-\gamma)-\mathrm{P}_{8} \mathrm{c}(\psi-\gamma)}{\mathrm{s}(\psi-\gamma)-\mathrm{P}_{7} \mathrm{c} \gamma-\mathrm{P}_{8} \mathrm{c}(\psi-\gamma)}=0 \\
\Rightarrow \Delta \mathrm{w} \Delta \psi \mathrm{s} \psi \frac{\partial \mathrm{y}}{\partial \mathrm{x}} \mathrm{P}_{5}+\left[\Delta \mathrm{y} \Delta \gamma \frac{\partial \mathrm{w}}{\partial \mathrm{x}}-\Delta \mathrm{w} \Delta \psi \frac{\partial \mathrm{y}}{\partial \mathrm{x}}\right] \mathrm{s}(\psi-\gamma) \mathrm{P}_{6}+\ldots \\
\ldots+\Delta \mathrm{y} \Delta \gamma \mathrm{c} \gamma \frac{\partial \mathrm{w}}{\partial \mathrm{x}} \mathrm{P}_{7}+\left[\Delta \mathrm{y} \Delta \gamma \frac{\partial \mathrm{w}}{\partial \mathrm{x}}-\Delta \mathrm{w} \Delta \psi \frac{\partial \mathrm{y}}{\partial \mathrm{x}}\right] \mathrm{c}(\psi-\gamma) \mathrm{P}_{8}=\Delta \mathrm{y} \Delta \gamma \mathrm{s} \gamma \frac{\partial \mathrm{w}}{\partial \mathrm{x}}
\end{gathered}
$$

Eq. (23) is linear in $\mathrm{P}_{5}, \mathrm{P}_{6}, \mathrm{P}_{7}$ and $\mathrm{P}_{8}$. Eq. (20) and Eq. (23) written for $\mathrm{x}_{4}$ and $\mathrm{x}_{5}$ constitute four equations in 5 unknowns $\left(\mathrm{P}_{4}, \mathrm{P}_{5}, \mathrm{P}_{6}, \mathrm{P}_{7}, \mathrm{P}_{8}\right)$. However, $\mathrm{P}_{8}=\mathrm{P}_{6} \mathrm{P}_{7}$, so not all $\mathrm{P}_{\mathrm{j}}$ 's are independent. Let $\mathrm{P}_{8}$ $=\lambda$ and $P_{j}=m_{j}+n_{j} \lambda$ for $j=4,5,6,7$. Substituting in Eq. (20) and Eq. (23):

- $\left(\mathrm{m}_{4}+\mathrm{n}_{4} \lambda\right)+\mathrm{c} \psi_{4}\left(\mathrm{~m}_{5}+\mathrm{n}_{5} \lambda\right)-\mathrm{c}\left(\psi_{4}-\gamma_{4}\right)\left(\mathrm{m}_{6}+\mathrm{n}_{6} \lambda\right)-\mathrm{s} \gamma_{4}\left(\mathrm{~m}_{7}+\mathrm{n}_{7} \lambda\right)=\mathrm{c} \gamma_{4}-\mathrm{s}\left(\psi_{4}-\gamma_{4}\right) \lambda$

- $\left(\mathrm{m}_{4}+\mathrm{n}_{4} \lambda\right)+\mathrm{c} \psi_{5}\left(\mathrm{~m}_{5}+\mathrm{n}_{5} \lambda\right)-\mathrm{c}\left(\psi_{5}-\gamma_{5}\right)\left(\mathrm{m}_{6}+\mathrm{n}_{6} \lambda\right)-\mathrm{s} \gamma_{5}\left(\mathrm{~m}_{7}+\mathrm{n}_{7} \lambda\right)=\mathrm{c} \gamma_{5}-\mathrm{s}\left(\psi_{5}-\gamma_{5}\right) \lambda$

- $\left.\Delta \mathrm{w} \Delta \psi \mathrm{s} \psi_{4} \frac{\partial \mathrm{y}}{\partial \mathrm{x}}\right|_{\mathrm{x}_{4}}\left(\mathrm{~m}_{5}+\mathrm{n}_{5} \lambda\right)+\mathrm{s}\left(\psi_{4}-\gamma_{4}\right)\left[\left.\Delta \mathrm{y} \Delta \gamma \frac{\partial \mathrm{w}}{\partial \mathrm{x}}\right|_{\mathrm{x}_{4}}-\left.\Delta \mathrm{w} \Delta \psi \frac{\partial \mathrm{y}}{\partial \mathrm{x}}\right|_{\mathrm{x}_{4}}\right]\left(\mathrm{m}_{6}+\mathrm{n}_{6} \lambda\right)+\ldots$

$$
\ldots+\left.\Delta \mathrm{y} \Delta \gamma \mathrm{c} \gamma_{4} \frac{\partial \mathrm{w}_{\mathrm{d}}}{\partial \mathrm{x}}\right|_{\mathrm{x}_{4}}\left(\mathrm{~m}_{7}+\mathrm{n}_{7} \lambda\right)=\left.\Delta \mathrm{y} \Delta \gamma s \gamma_{4} \frac{\partial \mathrm{w}}{\partial \mathrm{x}}\right|_{\mathrm{x}_{4}}-\mathrm{c}\left(\psi_{4}-\gamma_{4}\right)\left[\left.\Delta \mathrm{y} \Delta \gamma \frac{\partial \mathrm{w}}{\partial \mathrm{x}}\right|_{\mathrm{x}_{4}}-\left.\Delta \mathrm{w} \Delta \psi \frac{\partial \mathrm{y}}{\partial \mathrm{x}}\right|_{\mathrm{x}_{4}}\right] \lambda
$$

- $\left.\Delta \mathrm{w} \Delta \psi \mathrm{s} \psi_{5} \frac{\partial \mathrm{y}}{\partial \mathrm{x}}\right|_{\mathrm{x}_{5}}\left(\mathrm{~m}_{5}+\mathrm{n}_{5} \lambda\right)+\mathrm{s}\left(\psi_{5}-\gamma_{5}\right)\left[\left.\Delta \mathrm{y} \Delta \gamma \frac{\partial \mathrm{w}}{\partial \mathrm{x}}\right|_{\mathrm{x}_{5}}-\left.\Delta \mathrm{w} \Delta \psi \frac{\partial \mathrm{y}}{\partial \mathrm{x}}\right|_{\mathrm{x}_{5}}\right]\left(\mathrm{m}_{6}+\mathrm{n}_{6} \lambda\right)+\ldots$

$$
\ldots+\left.\Delta \mathrm{y} \Delta \gamma \mathrm{c} \gamma_{5} \frac{\partial \mathrm{w}_{\mathrm{d}}}{\partial \mathrm{x}}\right|_{\mathrm{x}_{5}}\left(\mathrm{~m}_{7}+\mathrm{n}_{7} \lambda\right)=\left.\Delta \mathrm{y} \Delta \gamma \mathrm{s} \gamma_{5} \frac{\partial \mathrm{w}}{\partial \mathrm{x}}\right|_{\mathrm{x}_{5}}-\mathrm{c}\left(\psi_{5}-\gamma_{5}\right)\left[\left.\Delta \mathrm{y} \Delta \gamma \frac{\partial \mathrm{w}}{\partial \mathrm{x}}\right|_{\mathrm{x}_{5}}-\left.\Delta \mathrm{w} \Delta \psi \frac{\partial \mathrm{y}}{\partial \mathrm{x}}\right|_{\mathrm{x}_{5}}\right] \lambda
$$

Equating coefficients of $\lambda$ and the rest to zero in Eq. (24) and writing in matrix form:

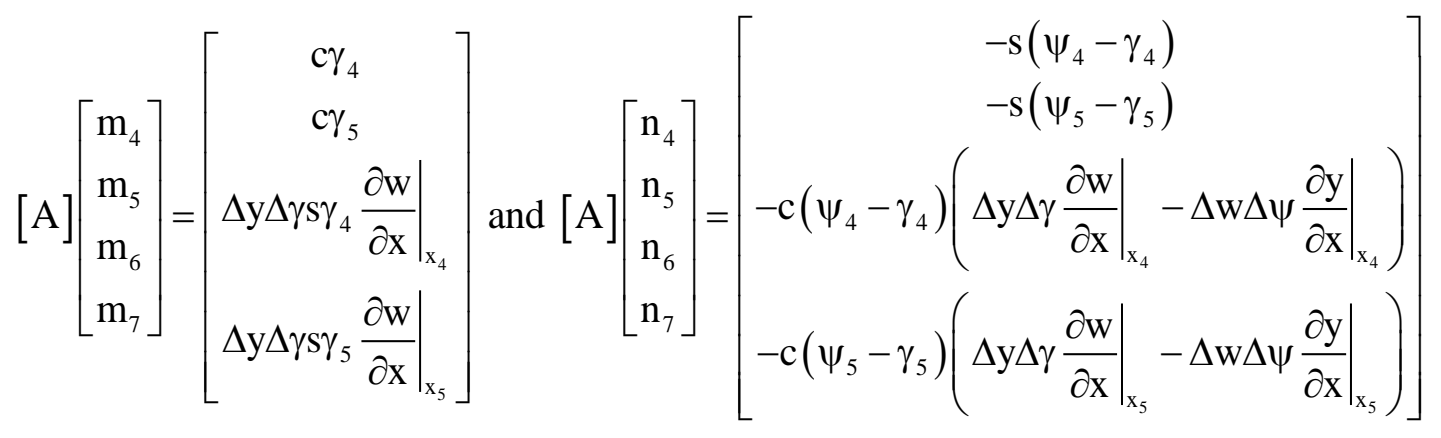

$$
\text { where }[\mathrm{A}]=\left[\begin{array}{cccc}
1 & \mathrm{c} \psi_{4} & -\mathrm{c}\left(\psi_{4}-\gamma_{4}\right) & -\mathrm{s} \gamma_{4} \\
1 & \mathrm{c} \psi_{5} & -\mathrm{c}\left(\psi_{5}-\gamma_{5}\right) & -\mathrm{s} \gamma_{5} \\
0 & \left.\Delta \mathrm{w} \Delta \psi \mathrm{s} \psi_{4} \frac{\partial \mathrm{y}}{\partial \mathrm{x}}\right|_{\mathrm{x}_{4}} & \mathrm{~s}\left(\psi_{4}-\gamma_{4}\right)\left(\left.\Delta \mathrm{y} \Delta \gamma \frac{\partial \mathrm{w}}{\partial \mathrm{x}}\right|_{\mathrm{x}_{4}}-\left.\Delta \mathrm{w} \Delta \psi \frac{\partial \mathrm{y}}{\partial \mathrm{x}}\right|_{\mathrm{x}_{4}}\right) & \left.\Delta \mathrm{y} \Delta \gamma \mathrm{c} \gamma_{4} \frac{\partial \mathrm{w}_{\mathrm{d}}}{\partial \mathrm{x}}\right|_{\mathrm{x}_{4}} \\
0 & \left.\Delta \mathrm{w} \Delta \psi \mathrm{s} \psi_{5} \frac{\partial \mathrm{y}}{\partial \mathrm{x}}\right|_{\mathrm{x}_{5}} & \mathrm{~s}\left(\psi_{5}-\gamma_{5}\right)\left(\left.\Delta \mathrm{y} \Delta \gamma \frac{\partial \mathrm{w}}{\partial \mathrm{x}}\right|_{\mathrm{x}_{5}}-\left.\Delta \mathrm{w} \Delta \psi \frac{\partial \mathrm{y}}{\partial \mathrm{x}}\right|_{\mathrm{x}_{5}}\right) & \left.\Delta \mathrm{y} \Delta \gamma \mathrm{c} \gamma_{5} \frac{\partial \mathrm{w}_{\mathrm{d}}}{\partial \mathrm{x}}\right|_{\mathrm{x}_{5}}
\end{array}\right] .
$$

$\mathrm{m}_{4}, \mathrm{~m}_{5}, \mathrm{~m}_{6}, \mathrm{~m}_{7}, \mathrm{n}_{4}, \mathrm{n}_{5}, \mathrm{n}_{6}$ and $\mathrm{n}_{7}$ are solved by inverting [A]. $\lambda$ is solved as follows: 


$$
\begin{gathered}
\lambda=\mathrm{P}_{8}=\mathrm{P}_{6} \mathrm{P}_{7}=\left(\mathrm{m}_{6}+\mathrm{n}_{6} \lambda\right)\left(\mathrm{m}_{7}+\mathrm{n}_{7} \lambda\right) \Rightarrow \mathrm{n}_{6} \mathrm{n}_{7} \lambda^{2}+\left(\mathrm{m}_{6} \mathrm{n}_{7}+\mathrm{n}_{6} \mathrm{~m}_{7}-1\right) \lambda+\mathrm{m}_{6} \mathrm{~m}_{7}=0 \\
\Rightarrow \lambda=\frac{1-\mathrm{m}_{6} \mathrm{n}_{7}-\mathrm{n}_{6} \mathrm{~m}_{7} \mp \sqrt{\left(\mathrm{m}_{6} \mathrm{n}_{7}+\mathrm{n}_{6} \mathrm{~m}_{7}-1\right)^{2}-4 \mathrm{~m}_{6} \mathrm{~m}_{7} \mathrm{n}_{6} \mathrm{n}_{7}}}{2 \mathrm{n}_{6} \mathrm{n}_{7}} \\
\end{gathered}
$$

Next, $P_{j}=m_{j}+n_{j} \lambda$ for $j=4,5,6,7$ are evaluated. Then $d$, e and $f$ are found as $f=P_{6}, \alpha=\tan ^{-1} P_{7}$,

$\mathrm{d}=\frac{\mathrm{f}}{\mathrm{P}_{5} \mathrm{c} \alpha}$ and $\mathrm{e}=\sqrt{1+\mathrm{d}^{2}+\mathrm{f}^{2}-2 \mathrm{dc \alpha} \mathrm{P}_{4}}$. Once again e should be real, if $\mathrm{d}$ is positive for $\alpha=\tan ^{-1} \mathrm{P}_{9}$, otherwise, $\alpha=\tan ^{-1} \mathrm{P}_{9}+\pi$ and if $\mathrm{f}$ is negative, $\pi$ can be added to limits of $\psi$. The error variation $\delta_{2}=$ $\mathrm{w}_{\text {desired }}-\mathrm{w}_{\text {generated } 2}$ is determined with at least three precision points with the right assembly mode of the loop. $\delta_{\mathrm{y}}=\mathrm{y}_{\text {desired }}-\mathrm{y}_{\text {generated }}$ is obtained and minimized by adjusting the angles and the intermediate function parameter while monitoring the necessary design considerations.

\section{Numerical Examples}

All formulations in the Section 3 are implemented in Excel and several different function synthesis tasks are performed. In this section, we present the application of each of the three correction methods for generation of a power function, an exponential function and a trigonometric function.

First function worked on is $y=x^{2}$ for $1 \leq x \leq 5 \cdot y=x^{2}$ is decomposed as $w=x^{k}$ and $y=w^{2 / k}$. Second function is $\mathrm{y}=\mathrm{e}^{0.5 \mathrm{x}}$ for $1 \leq \mathrm{x} \leq 5$ and the function is decomposed as $\mathrm{w}=\mathrm{e}^{0.5 \mathrm{x} / \mathrm{k}}$ and $\mathrm{y}=\mathrm{w}^{\mathrm{k}}$. For both of the functions, $\mathrm{k}$ is the intermediate function parameter. $\mathrm{k}$ is a design parameter which can be selected arbitrarily by the designer and can be adjusted to minimize the function generation error. The third function is $\mathrm{y}=\sin (\mathrm{x})$ for $0 \leq \mathrm{x} \leq \pi / 2$ and the function is decomposed as $\mathrm{w}=\tan (\mathrm{x} / 2)$ and $\mathrm{y}=$ $2 \mathrm{w} /\left(1+\mathrm{w}^{2}\right)$. In this case, there is no intermediate function parameter.

For the three correction methods, the mechanism angle limits and, if exists, the intermediate function parameter are varied to minimize the maximum absolute error $\left|\delta_{y}\right|$ max subject to the conditions that the maximum to minimum link length ratio $\left(\mathrm{r}_{11}\right)$ of the mechanism is less than 10 and $\Delta \phi, \Delta \gamma$ or $\Delta \psi$ is not less than $20^{\circ}$. Recall that the fixed link lengths are $\left|A_{0} B_{0}\right|=\left|B_{0} D_{0}\right|=1$, but the loops can be independently scaled as one wishes. Therefore, $r_{l 1}$ is monitored independently for the two loops, but the relative sizes of the two loops is also considered. Since there are 6 angle limits and 1 intermediate function parameter for the first two functions and no intermediate parameter for the last function, there is a 7 or 6 dimensional optimization space. Using the spin buttons in Excel, several trials can be performed in a short time to find an optimum solution. Use of complicated numerical optimization techniques is not necessary. After several trials for the three functions with the three correction methods, the resulting designed link lengths are provided in Tables 1,2 and 3 for $y=x^{2}, y=e^{0.5 x}$ and $y$ $=\sin (x)$, respectively.

Table 1. Intermediate function parameter, angle limits and designed link lengths of the 6-bar linkage for generation of $\mathrm{y}=\mathrm{x}^{2}$ for $1 \leq \mathrm{x} \leq 5$

\begin{tabular}{|c|c|c|c|c|c|c|c|c|c|c|c|c|c|c|c|c|c|}
\hline Method & $\mathrm{k}$ & $\phi_{0}$ & $\phi_{\mathrm{f}}$ & $\gamma_{0}$ & $\gamma_{\mathrm{f}}$ & $\psi_{0}$ & $\psi_{\mathrm{f}}$ & $\phi^{*}$ & $\mathrm{a}$ & $\mathrm{b}$ & $\mathrm{c}$ & $\alpha$ & $\mathrm{d}$ & $\mathrm{e}$ & $\mathrm{f}$ & $\mathrm{r}_{\text {ll }}$ & $\left|\delta_{\mathrm{y}}\right|_{\max }$ \\
\hline 1 & 1.2 & $155^{\circ}$ & $33^{\circ}$ & $99^{\circ}$ & $44^{\circ}$ & $230^{\circ}$ & $309^{\circ}$ & $0^{\circ}$ & 0.119 & 1.090 & 0.259 & $0^{\circ}$ & 0.379 & 1.052 & 0.303 & 9.177 & $6.91 \times 10^{-2}$ \\
\hline 2 & 1.2 & $80^{\circ}$ & $0^{\circ}$ & $110^{\circ}$ & $58^{\circ}$ & $82^{\circ}$ & $59^{\circ}$ & $73.4^{\circ}$ & 0.780 & 1.536 & 1.338 & $239.1^{\circ}$ & 1.873 & 4.534 & 2.347 & 4.534 & $2.97 \times 10^{-4}$ \\
\hline 3 & 1.3 & $247^{\circ}$ & $315^{\circ}$ & $170^{\circ}$ & $140^{\circ}$ & $60^{\circ}$ & $120^{\circ}$ & $0^{\circ}$ & 0.341 & 0.693 & 0.585 & $169.2^{\circ}$ & 0.459 & 0.635 & 0.160 & 6.244 & $2.15 \times 10^{-3}$ \\
\hline
\end{tabular}


Table 2. Intermediate function parameter, angle limits and designed link lengths of the 6-bar linkage for generation of $\mathrm{y}=\mathrm{e}^{0.5 \mathrm{x}}$ for $1 \leq \mathrm{x} \leq 5$

\begin{tabular}{|c|c|c|c|c|c|c|c|c|c|c|c|c|c|c|c|c|c|}
\hline Method & $\mathrm{k}$ & $\phi_{0}$ & $\phi_{\mathrm{f}}$ & $\gamma_{0}$ & $\gamma_{\mathrm{f}}$ & $\psi_{0}$ & $\psi_{\mathrm{f}}$ & $\phi^{*}$ & $\mathrm{a}$ & $\mathrm{b}$ & $\mathrm{c}$ & $\alpha$ & $\mathrm{d}$ & $\mathrm{e}$ & $\mathrm{f}$ & $\mathrm{r}_{\text {II }}$ & $\left|\delta_{\mathrm{y}}\right|_{\max }$ \\
\hline 1 & 2 & $159^{\circ}$ & $265^{\circ}$ & $250^{\circ}$ & $317^{\circ}$ & $205^{\circ}$ & $231^{\circ}$ & $0^{\circ}$ & 0.649 & 1.680 & 0.856 & $0^{\circ}$ & 5.477 & 4.711 & 1.571 & 5.477 & $4.08 \times 10^{-2}$ \\
\hline 2 & 2 & $273^{\circ}$ & $230^{\circ}$ & $120^{\circ}$ & $54^{\circ}$ & $133^{\circ}$ & $107^{\circ}$ & $148.2^{\circ}$ & 1.840 & 0.716 & 1.570 & $229^{\circ}$ & 1.893 & 2.903 & 1.423 & 2.903 & $1.81 \times 10^{-3}$ \\
\hline 3 & 2 & $159^{\circ}$ & $268^{\circ}$ & $248^{\circ}$ & $323^{\circ}$ & $205^{\circ}$ & $275^{\circ}$ & $0^{\circ}$ & 0.742 & 1.752 & 0.898 & $-61.0^{\circ}$ & 8.750 & 8.503 & 1.471 & 8.750 & $2.48 \times 10^{-2}$ \\
\hline
\end{tabular}

Table 3. Angle limits and designed link lengths of the 6-bar linkage for generation of $y=\sin (x)$ for $0 \leq$ $\mathrm{x} \leq \pi / 2$

\begin{tabular}{|c|c|c|c|c|c|c|c|c|c|c|c|c|c|c|c|c|}
\hline Method & $\phi_{0}$ & $\phi_{\mathrm{f}}$ & $\gamma_{0}$ & $\gamma_{\mathrm{f}}$ & $\psi_{0}$ & $\psi_{\mathrm{f}}$ & $\phi^{*}$ & $\mathrm{a}$ & $\mathrm{b}$ & $\mathrm{c}$ & $\alpha$ & $\mathrm{d}$ & $\mathrm{e}$ & $\mathrm{f}$ & $\mathrm{r}_{\text {II }}$ & $\left|\delta_{\mathrm{y}}\right|_{\max }$ \\
\hline 1 & $213^{\circ}$ & $75^{\circ}$ & $150^{\circ}$ & $45^{\circ}$ & $57^{\circ}$ & $105^{\circ}$ & $0^{\circ}$ & 1.577 & 1.973 & 1.994 & $180^{\circ}$ & 0.329 & 1.447 & 0.823 & 4.398 & $1.99 \times 10^{-3}$ \\
\hline 2 & $180^{\circ}$ & $96^{\circ}$ & $150^{\circ}$ & $270^{\circ}$ & $265^{\circ}$ & $185^{\circ}$ & $244.1^{\circ}$ & 0.684 & 0.422 & 0.514 & $177.3^{\circ}$ & 0.594 & 0.678 & 0.854 & 1.682 & $3.00 \times 10^{-3}$ \\
\hline 3 & $183^{\circ}$ & $90^{\circ}$ & $148^{\circ}$ & $80^{\circ}$ & $42^{\circ}$ & $90^{\circ}$ & $0^{\circ}$ & 0.705 & 1.128 & 0.816 & $255.2^{\circ}$ & 0.147 & 1.154 & 0.117 & 9.837 & $1.39 \times 10^{-3}$ \\
\hline
\end{tabular}

All error curves of the worked out nine examples will not be presented here. To illustrate, the error curves for generation of $y=x^{2}$ with correction method 2 is presented in Fig. 5.
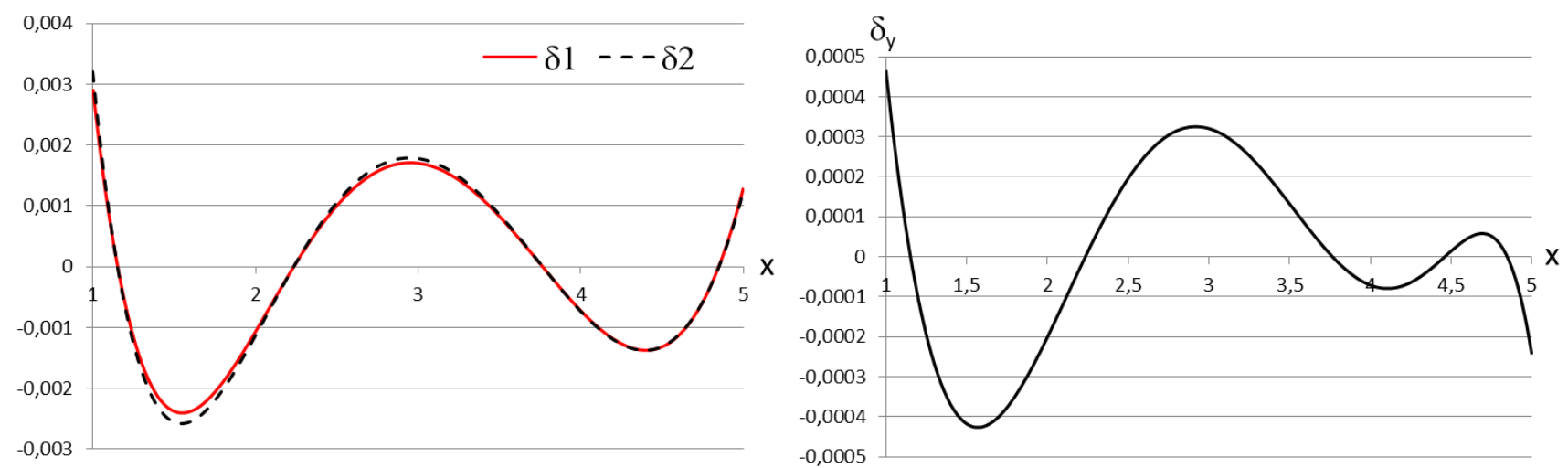

Fig. 5. Error curves for $y=x^{2}$ with correction method 2

\section{Performance Evaluation}

For $y=x^{2}$ and $y=e^{0.5 x}$, the solutions found for correction method 2 are superior than the solutions found for correction method 3 and correction method 1 yields the worst results. It is expectable that correction method 2 with four precision points is better than the correction method 1 with three precision points. On the other hand, we were expecting to get the best results with correction method 3, which makes use of the first order derivatives. Unlike the other two functions, for $y=\sin (x)$, correction method 3 gives the best results and correction method 2 gives the worst results. Once again, we do not claim that the results cannot be improved, however, the obtained numerical results indicate that any of the correction methods may be better than the others depending on the function to be generated and the domain of the independent variable.

Different types of mechanisms, different functions and different independent variable domains are used in the examples in the literature. Still, for comparing our results with the previously published results, we can take a look at the order of magnitudes of the errors. As a measure to be compared let us use the percentage error defined as

$$
\% \varepsilon=100 \cdot \mid \text { Maximum error }|/| \text { Range of the output } \mid
$$


For our examples the best results are as follows: $\% \varepsilon=0.00124 \%$ for $\mathrm{y}=\mathrm{x}^{2}$ with $1 \leq \mathrm{x} \leq 5, \% \varepsilon=$ $0.0172 \%$ for $\mathrm{y}=\mathrm{e}^{0.5 \mathrm{x}}$ with $1 \leq \mathrm{x} \leq 5$ and $\% \varepsilon=0.139 \%$ for $\mathrm{y}=\sin (\mathrm{x})$ with $0 \leq \mathrm{x} \leq \pi / 2$. The maximum percentage error we get is $0.139 \%$.

Kinzel et al. [17] designed a Stephenson III type six-bar linkage for generation of $y=\log _{10}(\mathrm{x})$ for $1 \leq$ $\mathrm{x} \leq 2$ with eleven precision points. The maximum error in the output of the function can be evaluated from the link lengths provided in the paper as $1.62 \times 10^{-5}$, so $\% \varepsilon=0.0054 \%$. For comparison, we also worked out $\mathrm{y}=\log _{10}(\mathrm{x})$ for $1 \leq \mathrm{x} \leq 2$ with Correction method 2, i.e. for four precision points for both loops. A good solution is obtained for the angle limits listed in Table 4. The percentage error is evaluated as $\% \varepsilon=0.0018 \%$ which is better than the error of Kinzel et al. [17]. But, note that the linkages utilized are of different type.

Table 4. Angle limits and designed link lengths of the 6-bar linkage for generation of $y=\log _{10}(\mathrm{x})$ for 1 $\leq \mathrm{x} \leq 2$

\begin{tabular}{|c|c|c|c|c|c|c|c|c|c|c|c|c|c|c|c|c|}
\hline Method & $\phi_{0}$ & $\phi_{\mathrm{f}}$ & $\gamma_{0}$ & $\gamma_{\mathrm{f}}$ & $\psi_{0}$ & $\psi_{\mathrm{f}}$ & $\phi^{*}$ & $\mathrm{a}$ & $\mathrm{b}$ & $\mathrm{c}$ & $\alpha$ & $\mathrm{d}$ & $\mathrm{e}$ & $\mathrm{f}$ & $\mathrm{r}_{11}$ & $\left|\delta_{\mathrm{y}}\right|_{\max }$ \\
\hline 2 & $40^{\circ}$ & $164^{\circ}$ & $60^{\circ}$ & $131^{\circ}$ & $1^{\circ}$ & $67^{\circ}$ & $45.03^{\circ}$ & 1.432 & 8.181 & 8.846 & $-32.5^{\circ}$ & 1.126 & 3.250 & 2.012 & 8.846 & $5.47 \times 10^{-6}$ \\
\hline
\end{tabular}

Hwang and Chen [18] designed a Stephenson II type function generator as an example for generation of $y=x^{2}$ for $-1 \leq x \leq 1$. The result is a maximum error of $0.498^{\circ}$ for an output range of $\Delta \theta=60^{\circ}$. This corresponds to a percentage error of $\% \varepsilon=0.83 \%$. Sancibrian [19] presented several design examples with different types of linkages for several different functions. The best result with the smallest magnitude of error is obtained with a Stephenson III type six-bar linkage for generation of a rise-dwellreturn type simple harmonic motion for $24^{\circ}$ oscillation of the output link. When the mechanism is analyzed, we found that the maximum amount of absolute error is $0.411^{\circ}$ within the range of $24^{\circ}$, which corresponds to a percentage error of $\% \varepsilon=1.71 \%$. These results are summarized in Table 5 .

Table 5. Comparison of designs

\begin{tabular}{|c|c|c|c|c|c|}
\hline Author & Function & $\begin{array}{c}\text { Input } \\
\text { domain }\end{array}$ & Output range & Linkage & $\boldsymbol{\%} \boldsymbol{\varepsilon}$ \\
\hline Kinzel et al. [17] & $\mathrm{y}=\log _{10}(\mathrm{x})$ & $1 \leq \mathrm{x} \leq 2$ & $0 \leq \mathrm{y} \leq 0.301$ & Stephenson III & $0.0054 \%$ \\
\hline Hwang and Chen [18] & $\mathrm{y}=\mathrm{x}^{2}$ & $-1 \leq \mathrm{x} \leq 1$ & $0 \leq \mathrm{y} \leq 1$ & Stephenson II & $0.83 \%$ \\
\hline Sancibrian [19] & $\mathrm{y}=\left\{\begin{array}{c}\pi[1-\cos (2 \mathrm{x})] / 30 \text { for } 0 \leq \mathrm{x} \leq \pi / 2 \\
\pi / 15 \quad \text { for } \pi / 2 \leq \mathrm{x} \leq 3 \pi / 2 \\
{[1-\cos (2 \mathrm{x})] / 30 \text { for } 3 \pi / 2 \leq \mathrm{x} \leq 2 \pi}\end{array}\right.$ & $0 \leq \mathrm{x} \leq 2 \pi$ & $0 \leq \mathrm{y} \leq 2 \pi / 15$ & Stephenson III & \multirow{2}{*}{$1.71 \%$} \\
\hline Kiper et al. & $\mathrm{y}=\log _{10}(\mathrm{x})$ & $1 \leq \mathrm{x} \leq 2$ & $0 \leq \mathrm{y} \leq 0.301$ & Watt II & $0.0018 \%$ \\
\hline Kiper et al. & $\mathrm{y}=\mathrm{x}^{2}$ & $1 \leq \mathrm{x} \leq 5$ & $1 \leq \mathrm{y} \leq 25$ & Watt II & $0.00124 \%$ \\
\hline Kiper et al. & $\mathrm{y}=\mathrm{e}^{0.5 \mathrm{x}}$ & $1 \leq \mathrm{x} \leq 5$ & $1.65 \leq \mathrm{y} \leq 12.2$ & Watt II & $0.0172 \%$ \\
\hline Kiper et al. & $\mathrm{y}=\sin (\mathrm{x})$ & $0 \leq \mathrm{x} \leq \pi / 2$ & $0 \leq \mathrm{y} \leq 1$ & Watt II & $0.139 \%$ \\
\hline
\end{tabular}

\section{Conclusions}

In this study, the method of decomposition is successfully applied to a Watt II type planar six-bar linkage. The method also can be easily adapted for the Stephenson III type planar six-bar linkage, as well, provided that the input link of the mechanism is a binary link connected to the ternary links. The three types of proposed correction methods are applied for three different functions: a power function, an exponential function and a trigonometric function. 
Using a two-loop function generator mechanism instead of a single-loop mechanism has the obvious advantage of reduced generation error. This can be seen by comparing the two plots in Fig. 5. The left plot for the single-loop mechanisms has errors in the order of $0.001 \mathrm{~s}$, while the right plot for the twoloop mechanism has errors in the order of $0.0001 \mathrm{~s}$. This is of course just an example, however it is natural to expect the superiority of a two-loop mechanism over a single-loop mechanism since the twoloop mechanism has more number of design parameters in total, regardless of it has been decomposed into two single-loops or not. Also via the examples presented in Section 5, we have demonstrated the power of the proposed methods in this study compared to the other methods presented in the literature for two-loop planar 6-bar mechanisms.

The application of the synthesis methods enclosed herein require specification of the six mechanism angle limits and, if exists, the intermediate function parameter by the designer. This gives the designer a flexibility in design. Although the selection of these six or seven design parameters is done manually in this study, it is also possible to run a numerical optimization technique with these free design parameters. We do not prefer to use such an optimization technique, because we want to see the changing behavior of the error variation as the free parameters are continuously varied. However, with this manual operation, we can only obtain limited number of feasible solutions and cannot guarantee that there is no better solution with less amount of error. Still, we can speculate on the results of the numerical examples in order to compare the three correction methods for the generation of the three different functions and conclude that superiority of the methods with respect to each other depends on the function to be generated.

\section{References}

[1] Alizade, R. I., Gezgin E. (2011). Synthesis of function generating spherical four bar mechanism for the six independent parameters. Mech. Mach. Theory, 46: 1316-1326.

[2] Norton, R. L. (2004). Design of Machinery: An Introduction to the Synthesis and Analysis of Mechanisms and Machines, $3^{\text {rd }}$ Ed., McGraw-Hill, §5.12.

[3] Rao, A. V. M., Sandor, G. N. (1971). Extension of Freudenstein's Equation to Geared Linkages. J. Eng. Ind, 93(1): 201-210.

[4] Alizade, R. I., Kiper, G., Bağdadioğlu, B., Dede, M. İ. C. (2014). Function synthesis of Bennett 6R mechanisms using Chebyshev approximation. Mech. Mach. Theory, 81: 62-78.

[5] Ali, H., Murray, A. P., Myszka, D. H. (2015). Reducing structural error in function generating mechanisms via the addition of large numbers of four-bar mechanisms. Proc. ASME 2015 International Design Engineering Technical Conferences \& Computers and Information in Engineering Conference. August 2-5, Boston, Massachusetts, USA, DETC2015-47457.

[6] Svoboda, A. (1948). Computing Mechanisms and Linkages, Dover Publications, §6.8.

[7] Alizade, R. I., Aydazade, K. P., Novruzbekov, I. G. (1980). Analysis and synthesis of planar mechanisms by using decomposition method, J. Mechanics of Machines, The Academy of Sciences of the USSR, 57, 26-32.

[8] McLarnan, C. W. (1963). Synthesis of six-link plane mechanisms by numerical analysis, ASME J. Eng. Ind., 85: 5-11.

[9] Rao, A. V. M, Erdman, A. G., Sandor, G. N., Raghunathan, V., Nigbor, D. E., Brown, L. E., Mahardy, E. F., and Enderle, E. D. (1971). Synthesis of multi-loop, dual-purpose planar mechanisms utilizing Burmester theory. In: Proc. The Second Applied Mechanism Conference, Stillwater, Olahoma, October 7-8, 7.1-7.23.

[10] Sandor, G. N., Erdman, A. G. (1984). Advanced Mechanism Design: Analysis and Synthesis, Vol. 2, Prentice-Hall, pp. 216-230.

[11] Dhingra A. K., Mani, N. K. (1993). Computer-aided mechanism design: a symbolic-computing approach. Comput. Aided Des., 25(5): 300-310.

[12] Dhingra A. K., Cheng, J. C., Kohli, D. (1994). Synthesis of six-link, slider-crank and four-link mechanisms for function, path and motion generation using homotopy with m-homogenization. ASME J. Mech. Des., 116(4): 11221131.

[13] Liu, A., Shi, B., Yang, T. (1995). On the kinematic synthesis of planar linkages with multi-loops. In: Proc. The Ninth World Congress on the Theory of Machines and Mechanisms, Milan, Italy, August 29-September 2, 95-97.

[14] Simionescu, P. A., Alexandru, P. (1995). Synthesis of function generators using the method of increasing the degree of freedom of the mechanism. In: Proc. The Ninth World Congress on the Theory of Machines and Mechanisms, Milan, Italy, August 29-September 2, 139-143. 
[15] Akçalı, İ. D. (1995). Modular approach to function generation. In: Proc. The Ninth World Congress on the Theory of Machines and Mechanisms, Milan, Italy, August 29-September 2, 1440-1444.

[16] Shiakolas, P. S., Koladiya, D., Kebrle, J. (2005). On the optimum synthesis of six-bar linkages using differential evolution and the geometric centroid of precision positions technique. Mech. Mach. Theory, 40: 319-335.

[17] Kinzel, E. C., Schmiedeler, J. P., Pennock, G. R. (2007). Function generation with finitely separated precision points using geometric constraint programming. ASME J. Mech. Des., 129:1185-1190.

[18] Hwang, W. M., Chen, Y. J. (2010). Defect-free synthesis of Stephenson-II function generators. ASME J. Mech. Rob., 2(4): 041012.

[19] Sancibrian, R. (2011). Improved GRG method for the optimal synthesis of linkages in function generation problems. Mech. Mach. Theory, 46(10): 1350-1375.

[20] Plecnik, M. M., McCarthy, J. M. (2014). Numerical synthesis of six-bar linkages for mechanical computation. J. Mech. Rob. 6(3): 031012.

[21] Plecnik, M. M., McCarthy, J. M. (2016). Computational design of Stephenson II six-bar function generators for 11 accuracy points. J. Mech. Rob. 8(1): 011017.

[22] Agarwal, S., Badduri, J., Bandyopadhyay, S. (2015). Optimal synthesis of six-bar function generators. In: Proc. 14 ${ }^{\text {th }}$ IFToMM World Congress, Taipei, Taiwan, October 25-30, DOI: 10.6567/IFToMM.14TH.WC.OS2.031.

[23] Maaroof, O. W., Dede, M. İ. C. (2013). A comparative study on application of decomposition method in function generation synthesis of over-constrained mechanisms. In: Petuya, V. et al. (Eds.), New Advances in Mechanisms, Transmissions and Applications, Mechanisms and Machine Science 17, Springer, 309-316.

[24] Maaroof, O. W., Dede, M. İ. C. (2014). Kinematic synthesis of over-constrained double-spherical six-bar mechanism. Mech. Mach. Theory, 73: 154-168.

[25] Maaroof, O. W., Dede, M. İ. C., Kiper, G. (2017). Alternating error effects on decomposition method in function generation synthesis, in: Wenger, P., Flores, P. (Eds.), New Trends in Mechanism and Machine Science - Theory and Industrial Applications, Springer, 293-301. 